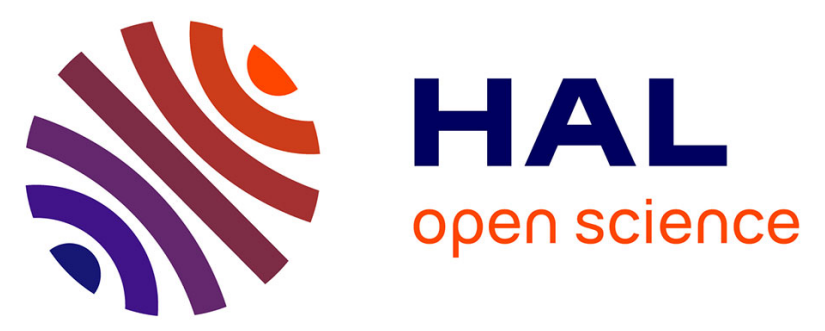

\title{
In situ glyco-nanostructure formulation via photo-polymerization induced self-assembly
}

Khalid Ferji, Pierre Venturini, Franck Cleymand, Christophe Chassenieux, Jean-Luc Six

\section{- To cite this version:}

Khalid Ferji, Pierre Venturini, Franck Cleymand, Christophe Chassenieux, Jean-Luc Six. In situ glyco-nanostructure formulation via photo-polymerization induced self-assembly. Polymer Chemistry, 2018, 9 (21), pp.2868-2872. 10.1039/C8PY00346G . hal-02058224

\section{HAL Id: hal-02058224 \\ https://hal.univ-lorraine.fr/hal-02058224}

Submitted on 18 Jan 2022

HAL is a multi-disciplinary open access archive for the deposit and dissemination of scientific research documents, whether they are published or not. The documents may come from teaching and research institutions in France or abroad, or from public or private research centers.
L'archive ouverte pluridisciplinaire HAL, est destinée au dépôt et à la diffusion de documents scientifiques de niveau recherche, publiés ou non, émanant des établissements d'enseignement et de recherche français ou étrangers, des laboratoires publics ou privés.

\section{(c)(1)}

Distributed under a Creative Commons Attribution| 4.0 International License 


\title{
In situ Glyco-nanostructures Formulation via Photo- Polymerization Induced Self-Assembly
}

\author{
Khalid Ferji, ${ }^{\mathrm{a}}$ Pierre Venturini, ${ }^{\mathrm{b}}$ Franck Cleymand, ${ }^{\mathrm{b}}$ Christophe Chassenieux, ${ }^{\mathrm{c}}$ Jean-Luc Six, ${ }^{\mathrm{a}}$
}

Frequently, the classical self-assembly techniques applied to amphiphilic glycopolymers lead to primitive morphologies, i.e. spherical micelles/nanoparticles. Herein, we report a facile and rapid one-pot synthesis and self-assembly of grafted amphiphilic glycopolymers using photo-initiated Polymerization-Induced SelfAssembly (Photo-PISA) under UV-irradiation at room temperature. Such glycopolymers were based on dextran as hydrophilic steric stabilizers backbone and poly(hydroxypropyl methacrylate) PHPMA as hydrophobic grafts. Transmission electron microscopy and light scattering analysis reveal formation of a broad set of advanced glyco-nanostructures ranging from spherical micelles to worm-like micelles and vesicles depending on both PHPMA grafts length and the solids content.

Over the last decades, polymeric nanostructures, ${ }^{1}$ including spherical/worm-like micelles and vesicles, have been extensively investigated and exploited in various application fields. In vivo drug/gene vectorization is particularly one of their most attractive applications. ${ }^{2}$ Nanostructures covered with poly(ethylene oxide) (PEO) ${ }^{3}$ have emerged as gold standard nanomaterials approved by the Food and Drug Administration (FDA), given the stealth properties of PEO. However, after almost a half-century of clinical uses, some studies have claimed that the intravenous injection of PEGylated carriers can induce formation of anti-PEO antibody, hypersensitivity reaction and complement activation. ${ }^{3 a, 4}$ Given their inherent biodegradability, immunogenicity and bioactivity, some neutral polysaccharides have been recently reported as suitable alternatives to PEO. ${ }^{5}$ Dextran is probably the most important neutral polysaccharide for medical and pharmaceutical industries. ${ }^{6}$ Owing to its hydrophilicity, nontoxicity and tunable biocompatibility, dextran has been approved by FDA as a plasma expander. ${ }^{7}$ During the last two decades, great achievements ${ }^{8}$ have been made regarding the synthesis of well-defined amphiphilic copolymers (called glycopolymers) combining hydrophilic natural polysaccharides and hydrophobic polymeric moieties, using mainly grafting from $^{9}$ and grafting onto ${ }^{10}$ strategies. However, more work is needed to optimize their self-assembly. Indeed, unlike synthetic polymeric amphiphiles which can easily selfassemble into a broad set of morphologies, ${ }^{2}$ only spherical micelles and core-shell nanoparticles have been systematically reported for glycopolymers. ${ }^{8}$ Reports on advanced glycopolymer-based nanostructures (glyco-nanostructures) morphologies such as nanocapsules ${ }^{11}$ and vesicles ${ }^{12}$ are actually scarce. This may be attributed to the unsuitable classical self-assembly processes currently used e.g. solvent exchange or nanoprecipitation. The use of an organic solvent which should be a good one from the thermodynamical point of view is a requirement that fails to be achieved for most of amphiphilic glycopolymers. Polymerization induced selfassembly (PISA) is an emerging one-pot technique enables to produce nanostructures based on self-assembled amphiphilic copolymers in aqueous media. In PISA, the aqueous radical polymerization of a suitable monomer, which forms a waterinsoluble polymer, is carried out using either a soluble macroinitiator or a macromolecular Chain Transfer Agent (macro-CTA). Amphiphilic copolymers are progressively obtained, leading to an in situ phase separation that finally generates stable colloidal polymeric nanostructures. Depending on the nature of the monomer used, PISA process could be performed either in emulsion polymerization, ${ }^{13}$ when using a water-insoluble monomer or in dispersion polymerization, ${ }^{14}$ with a water-soluble one. During the last five years, PISA has been extensively carried out using synthetic steric stabilizers, i.e. PEO $^{15}$ or poly(glycerol monomethacrylate) PGMA, ${ }^{16}$ with hydroxypropyl methacrylate (HPMA) as a watersoluble monomer leading to a water-insoluble biodegradable poly(hydroxypropyl methacrylate) (PHPMA) ${ }^{14}$. Some efforts have recently been devoted to use polysaccharides as efficient water-soluble steric stabilizers in PISA to produce glyconanostructures, but only spherical nanoparticles have been obtained and no higher order morphologies being achieved. Charleux and coworkers $^{13 b}$ reported preparation of submicronic latex particles using aqueous RAFT polymerization of vinyl acetate from a dextran derivative as a macro-CTA. Neufeld and coworkers ${ }^{13 c}$ demonstrated the formulation of spherical micelles when methyl methacrylate was polymerized from alginate macroinitiator in water/methanol mixture. Thermal initiation is currently the most commonly used way for aqueous PISA. ${ }^{14,17}$ However, some recent studies ${ }^{17,18}$ have reported an evolution of the nanostructures morphology reached at high temperature $\left(60^{\circ} \mathrm{C}-70^{\circ} \mathrm{C}\right.$, which is the range of temperature required for azo-initiators decomposition) after cooling to room temperature. To overcome this issue, photoPISA has recently emerged as a versatile alternative due to its facility, rapidity (99\% conversion within less than 1 hour) and ability to produce a broad range of nanostructures morphologies at room temperature. This approach can also afford temporal control of polymerization by switching the light "on" or "off", which facilitates the tracking of the polymerization progress and the isolation of nanostructures morphologies at defined conversion. ${ }^{19}$ In addition, owing to its mild experimental conditions, the photo-PISA should ensure a good reproducibility of the nanostructures morphologies. In this present study, PHPMA is grafted from a dextran backbone (Scheme 1) to demonstrate the ability for a dispersion photoPISA process to easily and rapidly prepare a broad set of advanced glyco-nanostructures. To the best of our knowledge, this work is the first report of a PISA using polysaccharide as steric stabilizer yielding high-ordered non-spherical morphologies. 
First, the photosensistive chain transfer agent 4-(propylthiocarbonothioylthio)-4-cyanopentanoic acid (TTC, 1, Scheme 1) was synthesized (Fig. S1+). ${ }^{20}$ The intensity (I) of the UV source (365 nm) was then optimized by carrying out the RAFT homopolymerization of HPMA in DMSO using TTC, without using an exogenous photoinitiator. Indeed, thiocarbonylthio compounds are known to act simultaneously as initiators and as evidenced from the linear evolutions of both $\ln \left([\mathrm{M}]_{0} /[\mathrm{M}]_{\mathrm{t}}\right)$ versus irradiation time and molecular weight versus monomer conversion and by the low dispersities $(\Theta<1.2)$ of PHPMA (Fig. $\mathrm{S}^{+}{ }^{+}$and $\mathrm{S} 3+$ ). Furthermore, TTC displays a better photolytic stability under $\mathrm{I}=27 \mathrm{~mW} . \mathrm{cm}^{-2}$ rather than higher one $\left(\mathrm{I}=53 \mathrm{~mW} . \mathrm{cm}^{-2}\right.$ ) (Fig. $\mathrm{S}^{+}+$and $\mathrm{S} 5+$ ). In the following, the UV irradiation intensity was fixed at $27 \mathrm{~mW} . \mathrm{cm}^{-2}$ to perform PISA

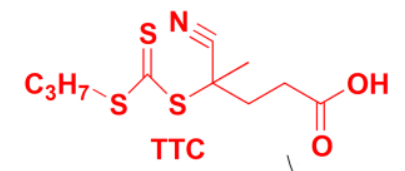

(1)

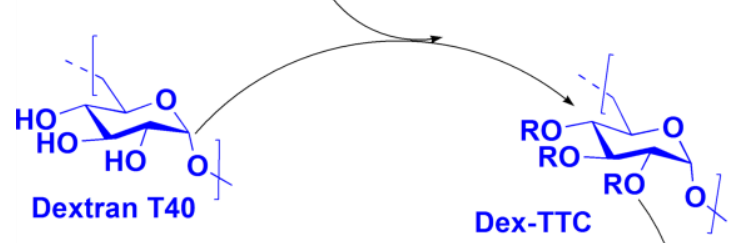

(2)

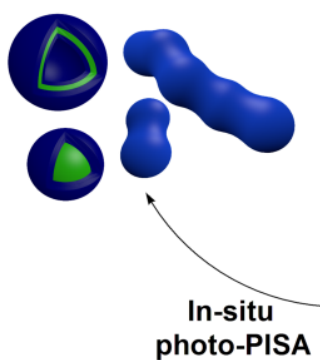

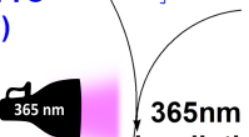
irradiation Water

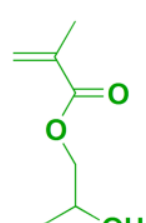

$\mathrm{OH}$ HPMA (1)<smiles>CC(=O)CCC(C)(C#N)SC(=S)C[OH2+]</smiles>
$\mathrm{C}_{3} \mathrm{H}_{7}-\mathrm{S}$

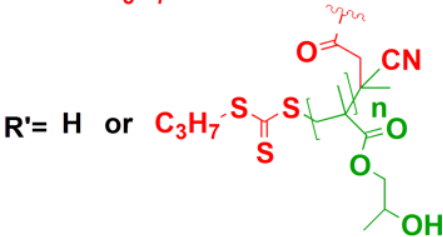

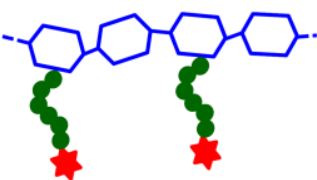

(3)

chain transfer agents, given the fragmentation of the weak C-S bond under UV irradiation. ${ }^{21}$ A very good control of the HPMA RAFT homopolymerization was observed with $\mathrm{I}=27 \mathrm{~mW} . \mathrm{cm}^{-2}$,

of dextran derivatives with HPMA grafts.

Scheme 1. Synthetic pathway of Dex-g ${ }^{\mathrm{N}}-\mathrm{PHPMA}_{\mathrm{y}}$-based glyco-nanostructures using aqueous photo-PISA process. N is the number average of PHPMA grafts per dextran chain. $y$ is the number-average degree of polymerization $\left(\overline{X_{n}}\right)$ of each PHPMA graft.

In a second step, the photo-macromolecular chain transfer agent Dex-TTC (2) based on dextran, was prepared through the partial esterification of some hydroxyl groups with TTC in the presence of $\mathrm{N}, \mathrm{N}^{\prime}$-carbonyldiimidazole (CDI) in DMSO (Scheme

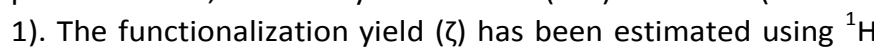
$\mathrm{NMR}$ in DMSO- $d_{6}$ (see Fig. S6+ for the detail of calculation). Here, 2.5 TTC were introduced per 100 glucopyranosic units meaning that Dex-TTC (2) contains about 5 TTC groups per

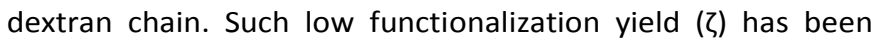
preselected to prevent precipitation of the glycopolymers that will be prepared. ${ }^{12 a}$

As shown in Scheme 1, Dex-TTC was then used to investigate the in situ RAFT aqueous dispersion polymerization of HPMA under UV irradiation leading to amphiphilic Dex-g $-\mathrm{g}^{5}-\mathrm{PHMA}_{Y}$ glycopolymers, where 5 is the number-average of PHPMA grafts per dextran chain and $Y$ is the number-average degree of polymerization $\left(\overline{X_{n}}\right)$ of each graft. Various Dex- $g^{5}-$ PHPMA $_{Y}$ glycopolymers has then been synthesized by varying the targeted graft length $\left(\overline{\mathrm{X}_{\mathrm{n}}}\right)$ and the final solids content (table 1 ). As evidenced from ${ }^{1} \mathrm{H}$ NMR analysis, a high conversion for
HPMA (>90\%) was reached within $10 \mathrm{~min}$ to $60 \mathrm{~min}$ of irradiation depending on the solids content (see Fig. $\mathrm{S}^{+}+$and S8+). A pretty good agreement between the theoretical $\left(\overline{\mathrm{M}_{\mathrm{n}}}\right.$ (the) $)$ and the experimental $\left(\overline{\mathrm{M}_{\mathrm{n}}}\right.$ (SEC) $)$ number average molecular weight was observed for all glycopolymers. SEC characterizations (Fig. S9+) indicates that Dex-g $-\mathrm{PHPMA}_{\mathrm{y}}$ displays relatively high dispersity $(\Theta)$. This is attributed to the large dispersity $(\Theta=1.8)$ of Dex-TTC macro-CTA used in the preparation of glycopolymers. SEC analysis of cleaved grafts (see Fig. $\mathrm{S10}^{+}$) shows chromatograms with narrow dispersity (1.1), which indicates that the grafts grow uniformly and in a controlled way from the dextran backbone. Examples of photo-PISA kinetics investigation of HPMA at $5 \% \mathrm{w} / \mathrm{w}$ and $20 \%$ $\mathrm{w} / \mathrm{w}$ solids content using Dex-TTC as the macro-CTA are presented in Fig. 1.

As shown in Fig. 1, whatever the solids content, the HMPA photo-PISA proceeds without any induction period, unlike its thermal analogue where an induction period of $50 \mathrm{~min}$ was reported. ${ }^{15}$ In addition, a non-linear evolution of $\ln \left([\mathrm{M}]_{\mathrm{O}} /[\mathrm{M}]_{\mathrm{t}}\right)$ versus time, which displays two time domains, was observed 
for both solids content. The first one observed at low conversion $(X<40 \%)$, which is characterized by a small slope of the $\ln \left([\mathrm{M}]_{0} /[\mathrm{M}]_{\mathrm{t}}\right.$ versus time, is related to growing grafts that remained soluble. RAFT polymerization proceeds then in a homogeneous aqueous medium. The Second domain, which is characterized by a higher slope, observed above $40 \%$ of

Table 1. Characteristics of Dex-g $-\mathrm{g}^{5}$-PHPMA glyco-nanostructures prepared by photo-PISA of HPMA in aqueous medium using Dex-TTC as the macro-CTA, at different solids content.

\begin{tabular}{|c|c|c|c|c|c|c|c|c|c|}
\hline Entry & $\begin{array}{c}\text { Solids } \\
\text { content }\end{array}$ & $\begin{array}{c}\text { Irradiation } \\
\text { time }\end{array}$ & Dex-g $-g^{5}-$ PHPMA & {$[\mathrm{HPMA}]_{0} /[\mathrm{TTC}]_{0}$} & $\begin{array}{l}X^{(a)} \\
(\%)\end{array}$ & $\begin{array}{l}{\overline{M_{n}}}_{\text {(SEC) }}{ }^{(b)} \\
\left(\mathrm{Kg} \mathrm{mol}^{-1}\right)\end{array}$ & $\begin{array}{c}{\overline{M_{n}}}_{\text {(the) }}{ }^{(c)} \\
\left(\mathrm{Kg} \mathrm{mol}^{-1}\right)\end{array}$ & $\bigoplus^{(\mathbf{b})}$ & $\mathbf{f}_{\text {dextran }}{ }^{\text {(d) }}$ \\
\hline$A$ & & & Dex-g ${ }^{5}-\mathrm{PHPMA}_{180}$ & $190 / 1$ & 95 & 144 & 163 & 1.6 & 0.22 \\
\hline B & $5 \%$ & $60 \mathrm{~min}$ & Dex-g $-g^{5}-\mathrm{PPMA}_{260}$ & $281 / 1$ & 93 & 217 & 221 & 1.6 & 0.16 \\
\hline $\mathrm{C}$ & & & Dex-g ${ }^{5}-\mathrm{PHPMA}_{340}$ & $370 / 1$ & 92 & 252 & 280 & 1.7 & 0.13 \\
\hline $\mathrm{D}$ & & & Dex-g $-g_{5}^{5}-\mathrm{PMA}_{105}$ & $110 / 1$ & 95 & 90 & 109 & 1.8 & 0.35 \\
\hline$E$ & $20 \%$ & $10 \mathrm{~min}$ & Dex-g ${ }^{5}-\mathrm{PHPMA}_{370}$ & $370 / 1$ & 100 & 273 & 300 & 2.0 & 0.12 \\
\hline $\mathrm{F}$ & & & Dex-g $^{5}-\mathrm{PHPMA}_{410}$ & $422 / 1$ & 97 & 297 & 330 & 1.7 & 0.11 \\
\hline
\end{tabular}

(a) Conversion of HPMA estimated by ${ }^{1} \mathrm{H}$ NMR analysis in DMSO- $d_{6}$.

(b) Number average molecular weight $\left(\overline{\mathrm{M}}_{\mathrm{n}}(\mathrm{SEC})\right.$ ) and dispersity $(\bigoplus)$ estimated by SEC analysis in $\mathrm{DMF} / \mathrm{LiCl}$ at $50^{\circ} \mathrm{C}$.

(c) Theoretical molecular weight calculated using Eq (1): $\overline{\mathrm{M}_{\mathrm{n}}}=5 \times \frac{[\mathrm{HPMA}]_{0}}{[\mathrm{TTC}]_{0}} \times \mathrm{y} \times \mathrm{M}_{\mathrm{HPMA}}+\mathrm{M}_{\text {DexTTC }}$ with $\mathrm{M}_{\mathrm{HPMA}}=144 \mathrm{~g} \cdot \mathrm{mol}^{-1}$ and $\mathrm{M}_{\text {Dex }}{ }_{T T C}=34 \mathrm{~kg} \cdot \mathrm{mol}^{-1}$.

(d) Weight fraction of dextran in Dex-g ${ }^{5}-$ PHPMA $_{\mathrm{y}}$ calculated using Eq (2): $\mathrm{f}_{\mathrm{dextran}}=\frac{\mathrm{M}_{\mathrm{dex}}}{\overline{\mathrm{M}_{\mathrm{n}}(\text { the })}}$, with $\mathrm{M}_{\mathrm{dex}}=32 \mathrm{Kg} \cdot \mathrm{mol}^{-1}$.

conversion, indicates that PHPMA grafts have reached a critical length and became water-insoluble, which drove from now on the self-assembly of Dex-g5-PHPMAy glycopolymers. The onset of selfassembly was defined as the conversion of HPMA at which solution started to become turbid (see Fig S11 ${ }^{+}$for turbidity and hydrodynamic radius evolutions with conversion). Such polymerization rate profile, which is generally observed in homogeneous medium, could suggest a gradual consumption of the TTC up to its full consumption, which causes a change in activation rate and thus the increase of the polymerization rate.

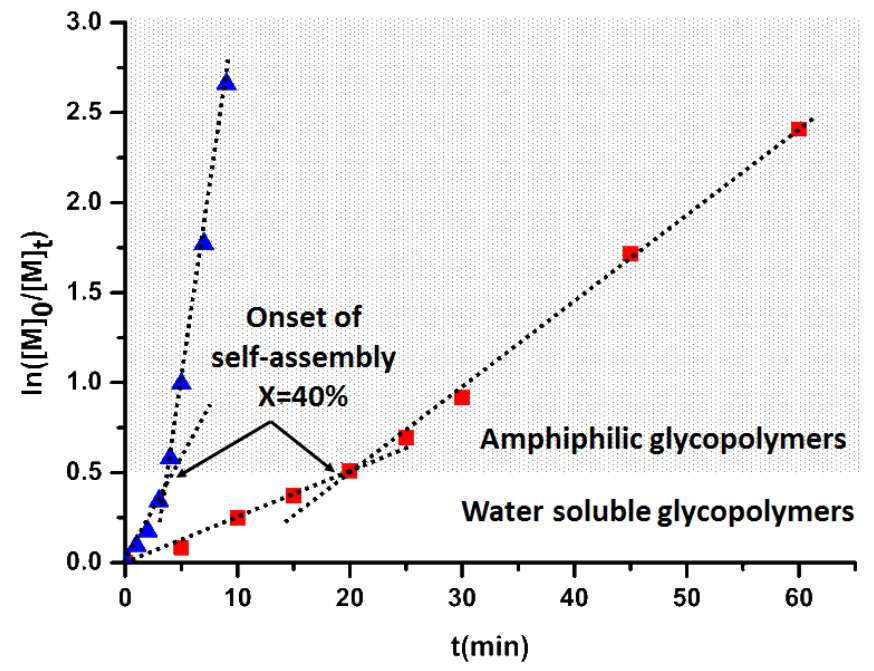

Fig. 1. Kinetics of the aqueous HPMA photo-PISA performed at ( $5 \% \mathrm{w} / \mathrm{w}$ and $(\boldsymbol{\Delta}) 20 \% \mathrm{w} / \mathrm{w}$ solids content using Dex-TTC as the macro-CTA. $[\text { HPMA }]_{0} /[\text { TTC }]_{0}=190 / 1$.

The photo-RAFT polymerization of HPMA was performed in DMSO, which is a good solvent for the Dex-g ${ }^{5}-\mathrm{PHPMA}_{\mathrm{y}}$ grafted glycopolymers, in order to check the consumption of the TTC in homogeneous medium (see Fig S12+). In this condition, the slope of the $\ln \left([\mathrm{M}]_{0} /[\mathrm{M}]_{\mathrm{t}}\right.$ versus time remained linear, which means that all TTC were consummated from the first instances of the polymerization and that the number of the active species remains constant during polymerization. However, the increase of the rate of polymerization is due to a high local residual HPMA concentration, which helps at solvating growing water-insoluble PHPMA grafts. This finding is qualitatively consistent with observations previously reported by Zhang and coworkers $^{19 a}$ for PHPMA-based diblock copolymers using PEO as a macro-CTA. We note that for Dex-g - PHPMA $_{y}$ grafted glycopolymers, the onset of self-assembly occurs when the size of PHPMA grafts reaches $\left(\overline{X_{n}}\right)$ equal to 76 (i.e. PHPMA ${ }_{76}$ ), which is smaller than the value $\left(\overline{X_{n}}=120\right)$ reported for PEO-bPHPMA diblock copolymers. ${ }^{19 a}$ This indicates that growing PHPMA chains are better solubilized within diblock copolymers, and that the number of grafts has a considerable effect on the onset of self-assembly.

The influence of the PHPMA grafts length $\left(\overline{\mathrm{X}_{\mathrm{n}}}\right)$ and of solids content on the glyco-nanostructures morphologies was systematically investigated by preparing various colloidal Dex$g^{5}-$ PHPMA $_{y}$-based nano-objects at two solids contents $(5 \%$ and $20 \% \mathrm{w} / \mathrm{w}$ ) (see table 1 and $\mathrm{S} 1$ ). Crude aqueous colloidal solutions of Dex-g - PHPMA $_{y}$ were first diluted, then characterized by Dynamic Light Scattering (DLS, Fig. 2) and observed by Transmission Electron Microscopy (TEM, Fig. 3) without any purification. Whatever the solids content, a single distribution of relaxation times over the whole scattering range (from q $=4.6 \times 10^{-4} \dot{A}^{-1}$ to $2.55 \times 10^{-3} \dot{A}^{-1}$ ) was observed by DLS. Typical examples of autocorrelation functions are presented in Fig. S13t. The relaxation time derived from the autocorrelation functions displayed a $\mathrm{q}^{2}$ dependence (Fig. $\left.\mathrm{S} 14^{+}\right)$, which means that diffusive motions of the scatterers were probed. This allows estimating their hydrodynamic radius $\left(R_{h}\right)$ using the Stokes-Einstein equation (Eq S1) since the samples were diluted enough prior to measurements to ensure that the interactions between the scatterers can be neglected.

Visual inspection of the samples (Fig. 2) shows that the turbidity of the final aqueous dispersions of glyco- 
nanostructures increases with the size of the PHPMA graft $\left(\overline{X_{n}}\right)$, as well as with $R_{h}$. We also note that the glyconanostructures display a relatively low PDI $(<0.25)$ and a pretty good colloidal stability upon ageing since their sizes remain almost unchanged after 4 months (Fig. 2). The increase of the size of the nano-objects with the length of PHPMA grafts may be attributed to a change of the morphology of the nanostructures, which has been investigated by TEM measurements (Fig. 3).

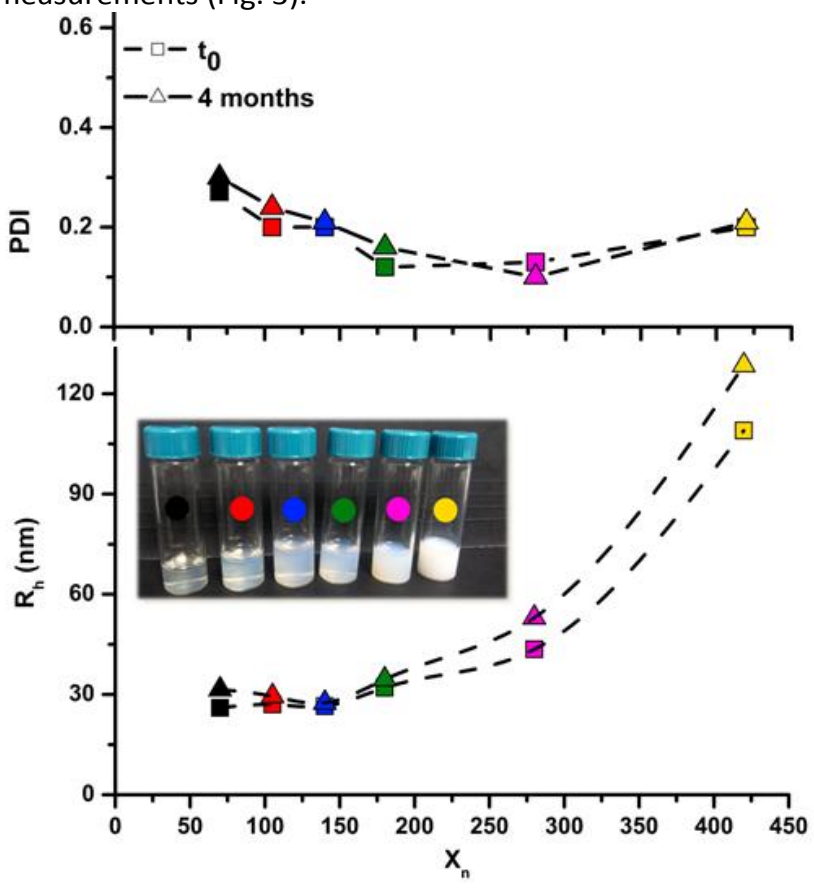

Fig. 2. Evolution of hydrodynamic radius $\left(R_{h}\right), P D I$ and visual inspection of the samples as a function of the grafts length $\left(\overline{\mathrm{X}_{\mathrm{n}}}\right)$. Dex-g ${ }^{5}-$ PHPMA $_{Y}$ colloidal dispersions were prepared at $5 \% \mathrm{w} / \mathrm{w}$ solids content, by photo-PISA of HPMA using Dex-TTC as the macroCTA.

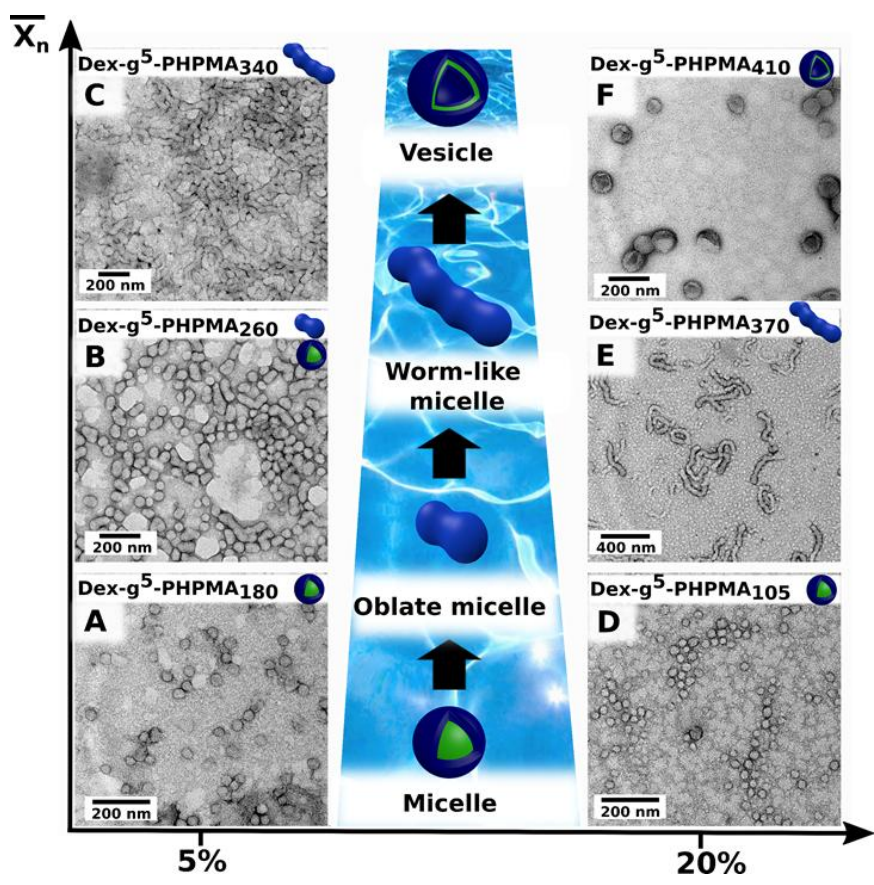

Fig. 3. TEM images of a series of Dex-g $-g^{5}-\mathrm{PHPMA}_{Y}$ based glyconanostructures prepared by aqueous photo-PISA of HPMA using Dex-TTC as the macro-CTA, at room temperature and with two solids contents $(5 \%$ and $20 \% \mathrm{w} / \mathrm{w})$ and $\mathrm{y}$ as targets. Samples were observed at $1 \mathrm{mg} \cdot \mathrm{mL}^{-1}$.

As shown in Fig. 3 a broad set of glyco-nanostructures morphologies has been achieved in situ including spherical micelles (Fig. 3A and $3 \mathrm{D}$ ), oblate micelles (in addition to the spherical micelles) (Fig. 3B), worm-like micelles (Fig. 3C and $3 \mathrm{E})$, and vesicles (Fig. $3 \mathrm{~F}$ ) depending on both grafts length $\left(\overline{\mathrm{X}_{\mathrm{n}}}\right)$ and the solids content. Indeed, with short PHPMA grafts $\left(\overline{\mathrm{X}_{\mathrm{n}}}<\right.$ 200), only spherical micelles were observed whatever the solids content. Oblate and worm-like micelles were observed by increasing the length of PHPMA grafts up to $\overline{X_{n}}=370$. Finally, at a high solids content $(20 \% \mathrm{w} / \mathrm{w})$, vesicular morphology was achieved with longer PHPMA grafts $\left(\overline{\mathrm{X}_{\mathrm{n}}}\right.$ $=410$ ). Additional TEM images of various Dex $-g^{5}-P_{H P M A}$ nanoobjects are available in Fig. S15t to S20t. To the best of our knowledge, this is the first time that such a broad set of highordered morphologies is observed with glycopolymers, especially oblate and worm-like morphologies. Such an evolution follows what has been previously reported by Armes and coworkers ${ }^{15}$ with PEO-b-PHPMA copolymers prepared by thermal-induced PISA. It has been established that transition from spheres to oblate micelles was due to the fusion of spherical micelles into dimers and then trimers. Such theory is confirmed in our case, since Fig. 3B shows a coexistence of spherical and oblate micelles. Furthermore, for diblock copolymers the morphology sequence can be rationalized in terms of hydrophobic / hydrophilic blocks volume ratio. ${ }^{22}$ For grafted glycopolymers such a rationale is more difficult to establish.

In summary and for the first time, we have demonstrated that glycopolymers could self-assemble into a broad set of advanced nanostructures morphologies, other than micelles and solid core-shell nanoparticles when using polymerization induced self-assembly (PISA) process. TEM observations and DLS measurements support an evolution of morphology of the glyco-nanostructures from spherical micelles to vesicles depending on both the glycopolymers concentration and the length of PHPMA grafts. A complete phase diagram and the influence of the number of grafts on the morphology of the glyco-nanostructures will be the subject of a future investigation. We believe that PISA process could be an efficient way for designing new smart biofriendly glyconanocarriers for drug/gene delivery or medical imaging.

\section{Conflicts of interest}

There are no conflicts to declare.

\section{Acknowledgements}


The authors thank O. Fabre for NMR characterization, C. Sejil for SEC characterization and J.-C. Sivault for UV lamp development.

\section{Notes and references}

1 D. E. Discher and A. Eisenberg, Science 2002, 297, 967.

2 Y. Mai and A. Eisenberg, Chem. Soc. Rev. 2012, 41, 5969.

3 (a) E. M. Pelegri-O'Day, E.-W. Lin, H. D. Maynard, J. Am. Chem. Soc. 2014, 136, 14323. (b) K. Ferji, I. Hamouda, C. Chassenieux, B. Nadal, B. Dubertret, C. Gaillard, E. Nicol, J. Colloid Interface Sci. 2016, 476, 222.

4 K. Knop, R. Hoogenboom, D. Fischer, U. S. Schubert, Angew. Chem. Int. Ed. 2010, 49, 6288.

5 M. A. Hussain, K. Abbas, I. Jantan, S. N. A. Bukhari, Int Mater. Rev. 2017, 62, 78.

6 T. Heinze, T. Liebert, B. Heublein, S. Hornig, polysaccharides II. Ed. Springer-Verlag Berlin: Berlin, 2006, 205, 199.

7 R. Mehvar, J. Control. Release. 2000, 69, 1.

8 Y. Miura, Y. Hoshino, H. Seto, Chem. Rev. 2016, 116, 1673.

9 (a) K. Ferji, C. Nouvel, J. Babin, P.-A. Albouy, M.-H. Li, J.-L. Six, J. Polym. Sci. Pol. Chem. 2013, 51, 3829. (b) R. Ouhib, B. Renault, H. Mouaziz, C. Nouvel, E. Dellacherie, J.-L. Six, Carbohydr. Polym. 2009, 77, 32. (c) L. Dupayage, C. Nouvel, J.- L. Six, J. Polym. Sci. Pol. Chem. 2011, 49, 35. (d) C. Nouvel, P. Dubois, E. Dellacherie, J.-L. Six, J. Polym. Sci. Pol. Chem. 2004, 42, 2577.

10 (a) S. M. A. Soliman, L. Colombeau, C. Nouvel, J. Babin, J.-L. Six, Carbohydr. Polym. 2016, 136, 598. (b) M. Laville, J. Babin I. Londono, M. Legros, C. Nouvel, A. Durand, R. Vanderesse, M. Leonard, J.-L. Six, Carbohydr. Polym. 2013, 93, 537.

11 K. Poltorak, A. Durand, M. Leonard, J.-L. Six, C. Nouvel, Colloid Surf. A-Physicochem. Eng. Asp. 2015, 483, 8.

12 (a) K. Ferji, C. Nouvel, J. Babin, M.-H. Li, C. Gaillard, E. Nicol, C. Chassenieux, J.-L. Six, ACS Macro Lett. 2015, 4, 1119. (b) C. Schatz, S. Louguet, J.-F. Le Meins, S. Lecommandoux, Angew. Chem. Int. Ed. 2009, 48, 2572.

13 (a) B. Charleux, G. Delaittre, J. Rieger, F. D'Agosto, Macromolecules 2012, 45, 6753. (b) J. Bernard, M. Save, B. Arathoon, B. J. Charleux, Polym. Sci. Pol. Chem. 2008, 46, 2845. (c) V. Kapishon, R. A. Whitney, P. Champagne, M. F. Cunningham, R. J. Neufeld, Biomacromolecules 2015, 16, 2040.

14 (a) N. J. Warren, S. P. Armes, J. Am. Chem. Soc. 2014, 136, 10174. (b) V. Ladmiral, M. Semsarilar, I. Canton, S.P. Armes, J. Am. Chem. Soc. 2013, 135, 13574.

15 N. J. Warren, O. O. Mykhaylyk, D. Mahmood, A. J. Ryan, S. P. Armes, J. Am. Chem. Soc. 2014, 136, 1023.

16 A. Blanazs, J. Madsen, G. Battaglia, A. J. Ryan, S. P. Armes, J. Am. Chem. Soc. 2011, 133, 16581.

17 Y. Pei, A. B. Lowe, P. Roth, J. Macromol. Rapid Commun. 2017, 38, 1600450.

18 J. Yeow, C. Boyer, Adv. Sci. 2017, 4, 1700137.

19 (a) J. B. Tan, H. Sun, M. G. Yu, B. S. Sumerlin, L. Zhang, ACS Macro Lett. 2015, 4, 1249. (b) J. Yeow, J. T. Xu, C. Boyer, ACS Macro Lett. 2015, 4, 984. (c) L. D. Blackman, K. E. B. Doncom, M. I. Gibson, R. K. O'Reilly, Polym. Chem. 2017, 8, 2860. (d) J. Yeow, O. R. Sugita, C. Boyer, ACS Macro Lett. 2016, 5, 558. (e) J. B. Tan, D. D. Liu, Y. H. Bai, C. D. Huang, X. L. Li, J. He, Q. Xu, X. C. Zhang, L. Zhang, Polym. Chem. 2017, 8, 1315. (f) G. $\mathrm{Ng}$, J. Yeow, J. Xu, C. Boyer, Polym. Chem. 2017, 8, 2841.

20 (a) G. Moad, Y. K. Chong, A. Postma, E. Rizzardo, S. H. Thang, Polymer 2005, 46, 8458. (b) J. A. Alfurhood, H. Sun, P. R. Bachler, B. S. Sumerlin, Polym. Chem. 2016, 7, 2099.

21 T. G. McKenzie, L. P. D. Costa, Q. Fu, D. E. Dunstan, G. G. Qiao, Polym. Chem. 2016, 7, 4246.

22 A. Blanazs, S. P. Armes, A. J. Ryan, Macromol. Rapid Commun. 2009, 30, 267. 


\section{Supporting information}

\section{In situ Glyco-nanostructures Formulation via Photo-Polymerization Induced Self-Assembly}

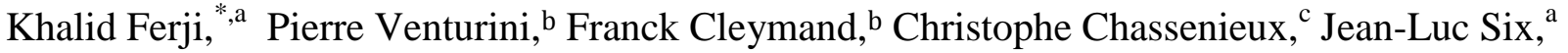

a. Université de Lorraine, LCPM, UMR-CNRS 7375, 1 rue Grandville BP20451 54000 NANCY (France)

b. Université de Lorraine, IJL, UMR-CNRS 7198, 2 allée André Guinier Campus Artem 54000 NANCY (France)

c. Le Mans Université, IMMM UMR-CNRS 6283, avenue Olivier Messiaen , 72085 Le Mans cedex (France).

E-mail: khalid.ferji@univ-lorraine.fr 


\section{MATERIALS AND METHODS}

Materials. Dextran $\mathrm{T}_{40}\left(\overline{M_{n}}=32,000\right.$ g.mol ${ }^{-1}, \mathrm{E}=1.4$, determined by SEC-MALLS, see below) was purchased from Pharmacia Biotech and dried under reduced pressure at $100{ }^{\circ} \mathrm{C}$ for one night prior to use. 1-propanethiol (99\%), carbone disulfide (>99\%), iodine (99.8\%), 4,4'-azobis(4cyanopentanoic acid) (98\%), N,N'-carbonyldiimidazole (CDI) (97\%), potassium tert-butoxide (95\%), lithium chloride (99\%), sodium thiosulfate, sodium sulfate, dimethylsulfoxide (DMSO) ( $\geq 99.9 \%), \mathrm{N}, \mathrm{N}$-dimethylformamide (DMF) (99.8\%), diethyl ether $\left(\mathrm{Et}_{2} \mathrm{O}\right)$, methanol $(\mathrm{MeOH})$ and ethyl acetate (99\%) were purchased from Sigma-Aldrich and used as received. 2-Hydroxypropyl methacrylate (HPMA) (98\%) was purchased from ABCR, purified by dissolving the monomer in water, then washed with hexane to remove diacrylates. After saturation of the aqueous solution by $\mathrm{NaCl}, \mathrm{HPMA}$ was extracted by $\mathrm{Et}_{2} \mathrm{O}$ to remove acrylic acid and dried over $\mathrm{MgSO}_{4}$ (3 wt \%). Finally, $\mathrm{Et}_{2} \mathrm{O}$ was evaporated off under reduced pressure at room temperature.

Synthesis of 4-(propylthiocarbonothioylthio)-4-cyanopentanoic acid RAFT agent (TTC) (1, Figure S1).

TTC was synthesized using a modified procedure previously reported ${ }^{1}$. 1-propanethiol (3.4 g, 45 $\mathrm{mmol}$ ) (1a, Figure S1) was added dropwise under nitrogen atmosphere at $5^{\circ} \mathrm{C}$ to a suspension of potassium tert-butoxide $(5 \mathrm{~g}, 45 \mathrm{mmol})$ in anhydrous $\mathrm{Et}_{2} \mathrm{O}(100 \mathrm{~mL})$ to provide a white slurry of potassium thiopropanate. After stirring the mixture for $20 \mathrm{~min}$, carbon disulfide $(3.4 \mathrm{~g}, 45$ $\mathrm{mmol}$ ) was introduced dropwise to the mixture at $0^{\circ} \mathrm{C}$ to provide a yellow precipitate of potassium-S-propyl trithiocarbonate, which was collected by filtration and used directly without purification. Afterwards, solid iodine $(5.9 \mathrm{~g}, 23 \mathrm{mmol})$ was added portion-wise to a stirred suspension of potassium-S-propyl trithiocarbonate $(8 \mathrm{~g}, 42 \mathrm{mmol})$ in anhydrous $\mathrm{Et}_{2} \mathrm{O}(200 \mathrm{~mL})$. After stirring the mixture for $2 \mathrm{~h}$ at room temperature, the white solid of potassium iodide was filtered and the brown filtrate was washed three times with an aqueous solution of sodium thiosulfate to remove excess iodine, then dried over sodium sulfate. After evaporation of $\mathrm{Et}_{2} \mathrm{O}, \mathrm{a}$ red oil of bis-(propanesulfyanyl thiocarbonyl)disulfide (4 g, $13.2 \mathrm{mmol}$ ) (1b, Figure S1) was obtained and characterized by ${ }^{1} \mathrm{H}$ NMR spectroscopy in $\mathrm{CDCl}_{3}$.

A solution of bis-(propanesulfyanyl thiocarbonyl) disulfide (2 g, $7 \mathrm{mmol}$ ) and 4,4'-azobis(4cyanopentanoic acid) $(2.8 \mathrm{~g}, 10 \mathrm{mmol})$ in ethyl acetate $(40 \mathrm{~mL})$ was heated under reflux for $24 \mathrm{~h}$. 
After removal of solvent, the crude product was solubilized in $\mathrm{Et}_{2} \mathrm{O}$, washed five times with deionized water, and finally dried under vacuum to obtain an oily product. Propyl 2cyanopropan-2-yl-carbonotrithioate $(2.6 \mathrm{~g}, 9.4 \mathrm{mmol})$ (1) was analyzed by ${ }^{1} \mathrm{H} \mathrm{NMR}$ in $\mathrm{CDCl}_{3}$ (Figure S1).

\section{Synthesis of the macromolecular Chain Transfer Agent (Dex-TTC) (2, Figure S6).}

Dex-TTC containing 5 TTC groups per dextran chain, was prepared via the partial esterification of hydroxyl groups of dextran with carboxylic acid function of TTC in the presence of $\mathrm{N}, \mathrm{N}^{\prime}$ carbonyldiimidazole (CDI). CDI (0.3 g, $1.5 \mathrm{mmol})$ and TTC $(0.4 \mathrm{~g}, 1.5 \mathrm{mmol})$ were dissolved in anhydrous DMSO $(20 \mathrm{~mL})$ and stirred at $40^{\circ} \mathrm{C}$ for $6 \mathrm{~h}$ to produce the activated acid imidazolide. Afterwards, the acid imidazolide reaction mixture was added under nitrogen atmosphere to a solution of dextran (2g, $12.3 \mathrm{mmol}$ glucopyranosic units) in DMSO previously prepared in a separate flask. The reaction was kept under stirring for $72 \mathrm{~h}$ at $60^{\circ} \mathrm{C}$. Finally, the crude product was precipitated in $\mathrm{MeOH}$. Dex-TTC was collected by filtration, dried under reduced pressure (yield $=80 \%$ ), and then analyzed by ${ }^{1} \mathrm{H}$ NMR in DMSO- $d_{6}$ (Figure S6).

\section{Photoinitiated RAFT homopolymerization of HPMA in DMSO.}

In a dried schlenk flask, HPMA $(2.5 \mathrm{~g}, 17.4 \mathrm{mmol})$ and TTC $(16 \mathrm{mg}, 0.058 \mathrm{mmol})$ were dissolved in dried DMSO $(5.1 \mathrm{~mL})$. The homogeneous mixture was purged with nitrogen for $10 \mathrm{~min}$, sealed, and then irradiated with a UV lamp $(365 \mathrm{~nm})$ using suitable light intensity $\left(4 \mathrm{~mW} / \mathrm{cm}^{-2}\right.$, $27 \mathrm{~mW} / \mathrm{cm}^{-2}, 45 \mathrm{~mW} / \mathrm{cm}^{-2}$ or $53 \mathrm{~mW} / \mathrm{cm}^{-2}$ ) at room temperature. Samples were taken under nitrogen at different time and the polymerization was quenched by exposure to air and addition of a small amount of hydroquinone. Crude product was then analyzed by ${ }^{1} \mathrm{H}$ NMR in DMSO- $d_{6}$ and by SEC-MALLS in DMF at $50^{\circ} \mathrm{C}$ (Figures S2 and S3).

\section{In-situ preparation of Dex-g $-\mathrm{P}^{5} \mathrm{PPMA}_{260}$-based nano-objects via aqueous photo polymerization-induced self-assembly.}

In a typical experiment for the synthesis of Dex-g ${ }^{5}-$ PHPMA $_{260}$, HPMA (1.18 g, $8.2 \mathrm{mmol}$ ) and DexTTC (0.2 g, $1.2 \mathrm{mmol}$ glucopyranosic units) were dissolved in a dried schlenk flask using a suitable volume of water to obtain a $5 \% \mathrm{w} / \mathrm{w}$ solids content $(26.4 \mathrm{~mL})$. The homogeneous mixture was purged with nitrogen for $10 \mathrm{~min}$, sealed, and then irradiated at room temperature 
with a UV lamp (365 nm, light intensity of $27 \mathrm{~mW} / \mathrm{cm}^{-2}$ ) for $1 \mathrm{~h}$ to achieve a full conversion. A small aliquot of the obtained dispersion was taken. One portion was freeze-dried and analyzed by ${ }^{1} \mathrm{H}$ NMR in DMSO- $d_{6}$ (Figure S7) and by SEC-MALLS in DMF/LiCl at $50^{\circ} \mathrm{C}$ (Figure S9). The other portion was characterized by TEM (Figures S15 to S20).

\section{Kinetics of photoinitiated aqueous RAFT dispersion polymerization of Dex-g $-g^{5}-P_{P M A} A_{180}$.}

In a typical experiment for the synthesis of Dex-g $-\mathrm{g}^{5}-\mathrm{PHMA}_{180}, \mathrm{HPMA}(0.8 \mathrm{~g}, 5.5 \mathrm{mmol})$ and DexTTC (0.2 g, $1.2 \mathrm{mmol}$ glucopyranosic units) were dissolved in a dried schlenk flask and using a suitable volume of $\mathrm{D}_{2} \mathrm{O}$ to obtain a $5 \% \mathrm{w} / \mathrm{w}$ solids content $(19 \mathrm{~mL})$. The homogeneous mixture was purged with nitrogen for $10 \mathrm{~min}$, sealed, and then irradiated with a UV lamp (365 nm, light intensity of $27 \mathrm{~mW} / \mathrm{cm}^{-2}$ ) at room temperature. Samples were taken under nitrogen at different times and the polymerization was stopped by exposure to air and addition of a small amount of hydroquinone. Crude product was then analyzed by ${ }^{1} \mathrm{H}$ NMR in DMSO- $d_{6}$ and by SEC-MALLS in DMF at $50^{\circ} \mathrm{C}$.

\section{Cleavage of the PHPMA grafts from Dextran Backbone}

In a typical experience of cleavage of PHPMA grafts from the glycopolymer Dex-g $-\mathrm{PHPMA}_{180}, 1 \mathrm{~mL}$ of the crude aqueous suspension ( $5 \% \mathrm{w} / \mathrm{w}$ solids content) was mixed with $2 \mathrm{~mL}$ of alkaline solution of $\mathrm{NaOH}$ (1 mol. $\mathrm{L}^{-1}$ ) for 24 hours at $50{ }^{\circ} \mathrm{C}$ to hydrolyze the ester functions linking grafts to dextran backbone. The white precipitate (PHPMA) that formed was recovered by centrifugation, washed 1 times with aqueous solution of $\mathrm{HCl}(1 \mathrm{~mol} . \mathrm{L}-1)$ and two times with distillated water, dried overnight at $50{ }^{\circ} \mathrm{C}$ under vacuum, then analyzed by SEC-MALLS in DMF at $50^{\circ} \mathrm{C}$ (see Figure S...).

\section{Polymer Analysis.}

${ }^{1} \mathrm{H} N M R$ spectra of products were recorded on a Bruker Avance 300 apparatus $(300,13 \mathrm{MHz}$, $25^{\circ} \mathrm{C}$ ) in $\mathrm{CDCl}_{3}$ or DMSO- $d_{6}$.

Size Exclusion chromatography (SEC). The molecular weights were measured using a SEC in

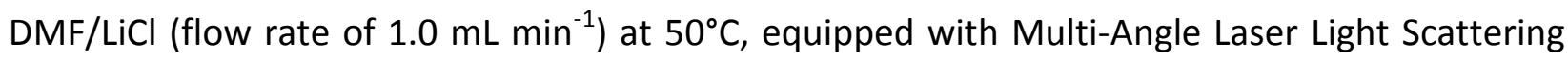
(MALLS) detector (Mini Dawn Wyatt), differential refractometer detector (RID 10A, Shimadzu), HPLC pump (LC 20AD, Shimadzu), degazer AF (DGU - 20A3R, Shimadzu), and three PLgel columns (100000, 1000, and $100 \AA$ ). Refractive index increments (dn/dc) of 0.01 was measured 
for all polymers (PHPMA, Dextran, Dex-TTC and Dex-g-PHPMA) in DMF/LiCl at $50^{\circ} \mathrm{C}$ using a differential refractometer from WYATT Technology (Optilab rEX and HELEOS-II).

\section{Dynamic Light Scattering (DLS).}

Hydrodynamic radii and size distribution of glycopolymers nano-objects were determined at $20^{\circ} \mathrm{C}$ using Dynamic Light Scattering. Samples were diluted 500-fold with water to produce $0.01 \% \mathrm{w} / \mathrm{w}$ solids content. Measurements were recorded using an ALV-5000 multitau correlator system in combination with a vertically polarized helium-neon laser with a wavelength of $\lambda=$ $632.8 \mathrm{~nm}$. The autocorrelation functions were analyzed in terms of relaxation time $(\mathrm{t})$ distribution according to REPES routine. ${ }^{2}$ Measurements were done at angles $\theta$ varying from $30^{\circ}$ to $150^{\circ}$ corresponding to scattering wave vectors q ranging from q $=4.6 \times 10^{-4} \dot{A}^{-1}$ to $2.55 \times 10^{-3}$ $\dot{A}^{-1}$. Z-average hydrodynamic radius $\left(\mathrm{R}_{\mathrm{h}}\right)$ was estimated using the Stokes-Einstein relation (EqS1), where $D_{0}$ is diffusion coefficient determined from the slope of the $q^{2}$ dependence of relaxation rate $\left(\langle\Gamma\rangle=D q^{2}\right), k_{B}$ is the Boltzmann constant, $T$ is experimental temperature and $\eta_{s}$ is the viscosity of the solvent (water).

$R_{h}=\frac{K_{B} \times T}{6 \times \pi \times \eta_{s} \times D_{0}}$

\section{Turbidity measurement.}

Evolution of the turbidity with conversion of PHPMA, during preparation of glyconanostructures via PISA process, was estimated by measuring transmittance of suspension at predefined time during UV-irradiation. Transmittance was measured at $600 \mathrm{~nm}$ using UVikon-XL spectrometer (Bio-Tech instruments) (see Figure S10).

\section{Transmission Electron Microscopy (TEM).}

The glycopolymers-based nano-objects were investigated by Transmission Electron Microscopy (TEM) using a microscope Philips CM200 operating at an accelerative voltage of 200kV. Images were recorded with a post-column camera Gatan MSC600. Samples were diluted 50-fold with water to produce $0.1 \% \mathrm{w} / \mathrm{w}$ solids content. A drop of the solution was adsorbed onto a copper grid for $30 \mathrm{~s}$, and then blotted with filter paper to remove excess solution. A drop of uranyl 
acetate solution $(0.5 \mathrm{wt} \%)$ was soaked on the sample-loaded grid for $30 \mathrm{~s}$, and then blotted with filter paper to remove excess stain.

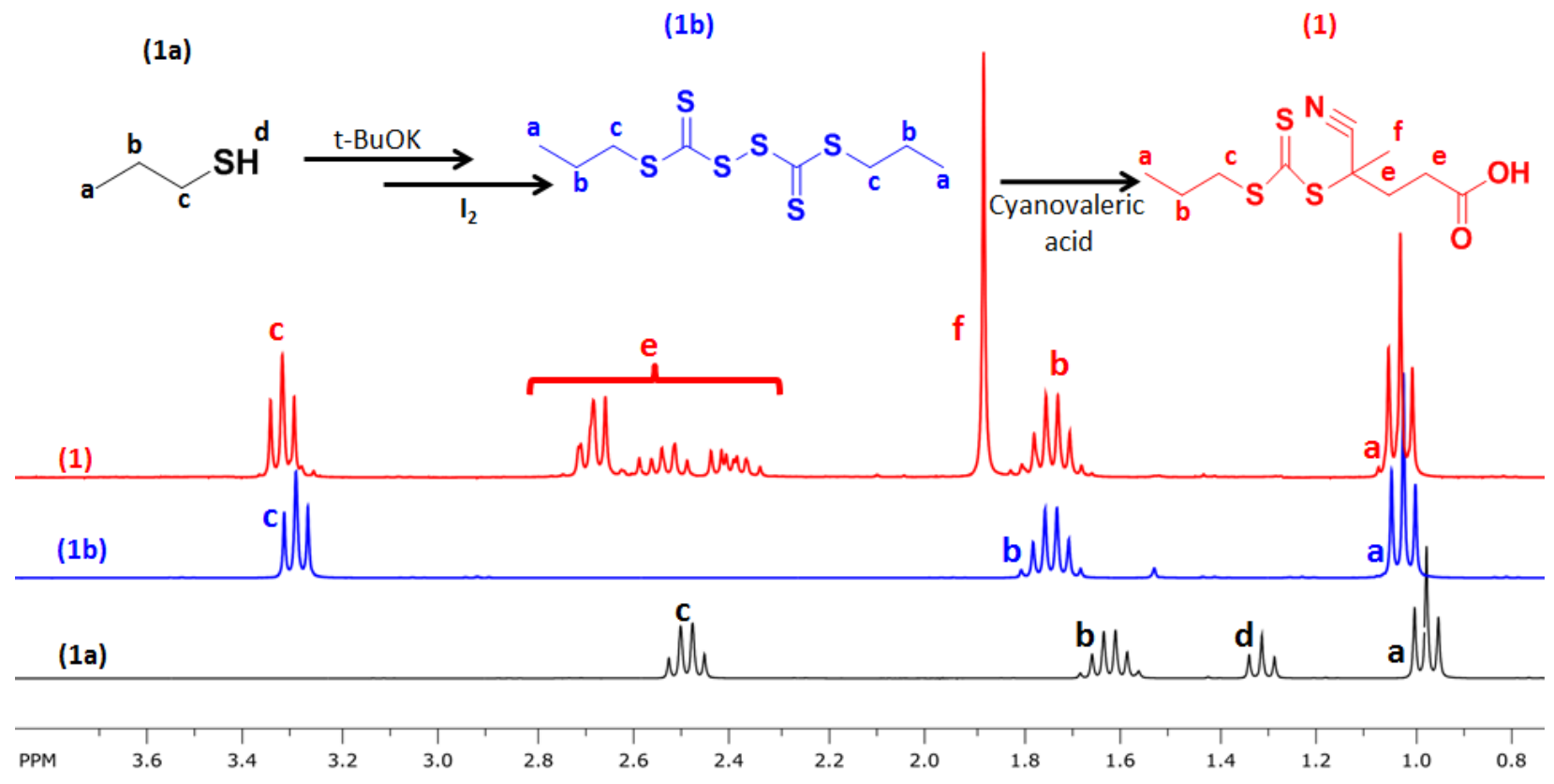

Figure S1. ${ }^{1} \mathrm{H}$ NMR spectra of 1-propanethiol (1a), bis-(propanesulfyanyl thiocarbonyl) disulfide (1b) and 4-(propylthiocarbonothioylthio)-4-cyanopentanoic acid (TTC) (1) in $\mathrm{CDCl}_{3}$. 

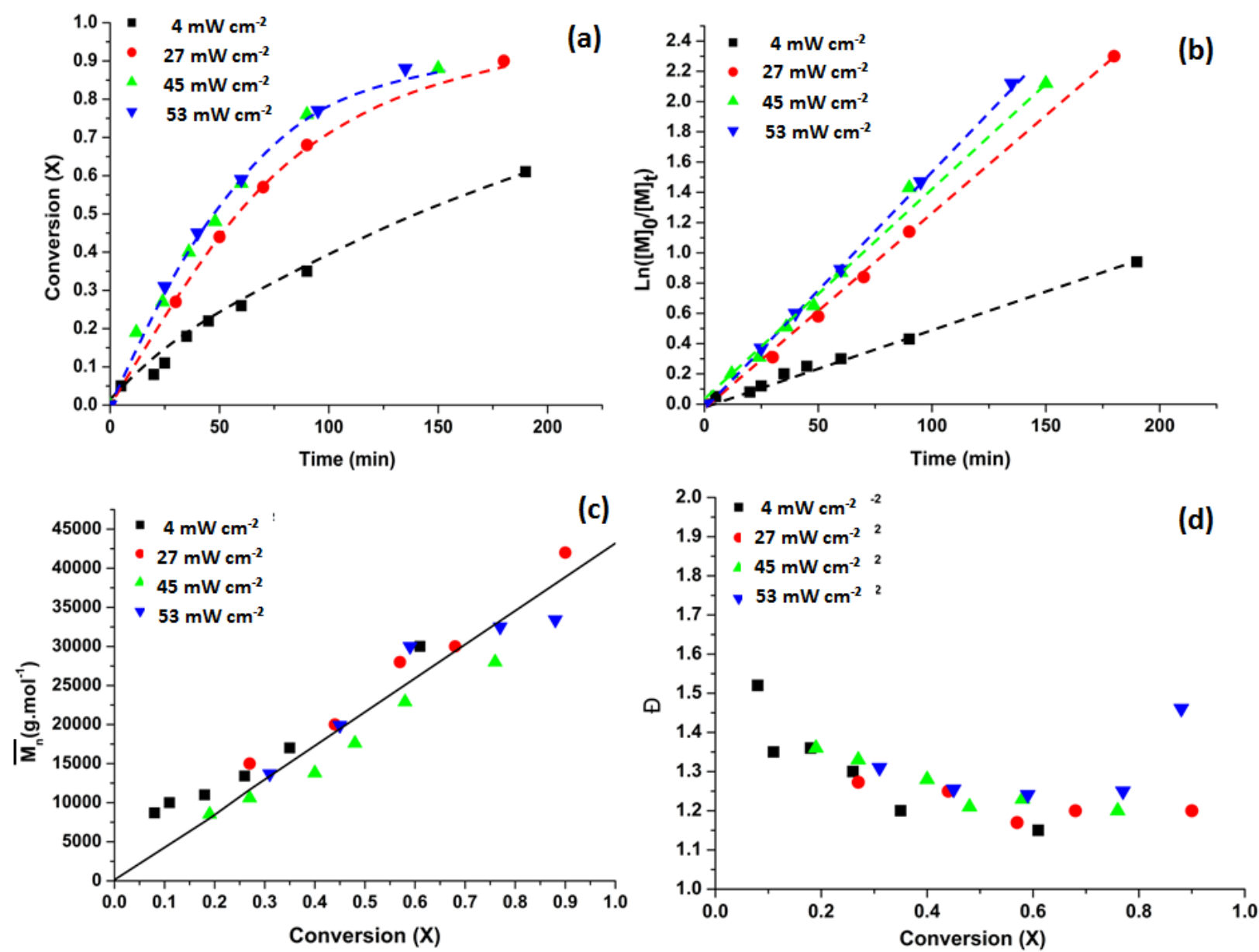

Figure S2. RAFT homopolymerization of HPMA in DMSO at room temperature, using TTC (1) with various UV lamp intensities $\left(4 \mathrm{~mW} / \mathrm{cm}^{-2}, 27 \mathrm{~mW} / \mathrm{cm}^{-2}, 45 \mathrm{~mW} / \mathrm{cm}^{-2}\right.$ or $\left.53 \mathrm{~mW} / \mathrm{cm}^{-2}\right)$. [HPMA $]_{0} /[\mathrm{TTC}]_{0}=300 / 1$. Plots of (a) conversion and (b) $\ln [\mathrm{M}]_{0} /[\mathrm{M}]_{\mathrm{t}}$ versus time. Plots of (c) $\overline{\mathrm{M}_{\mathrm{n}}}$ and (d) $\oplus$ versus conversion. 

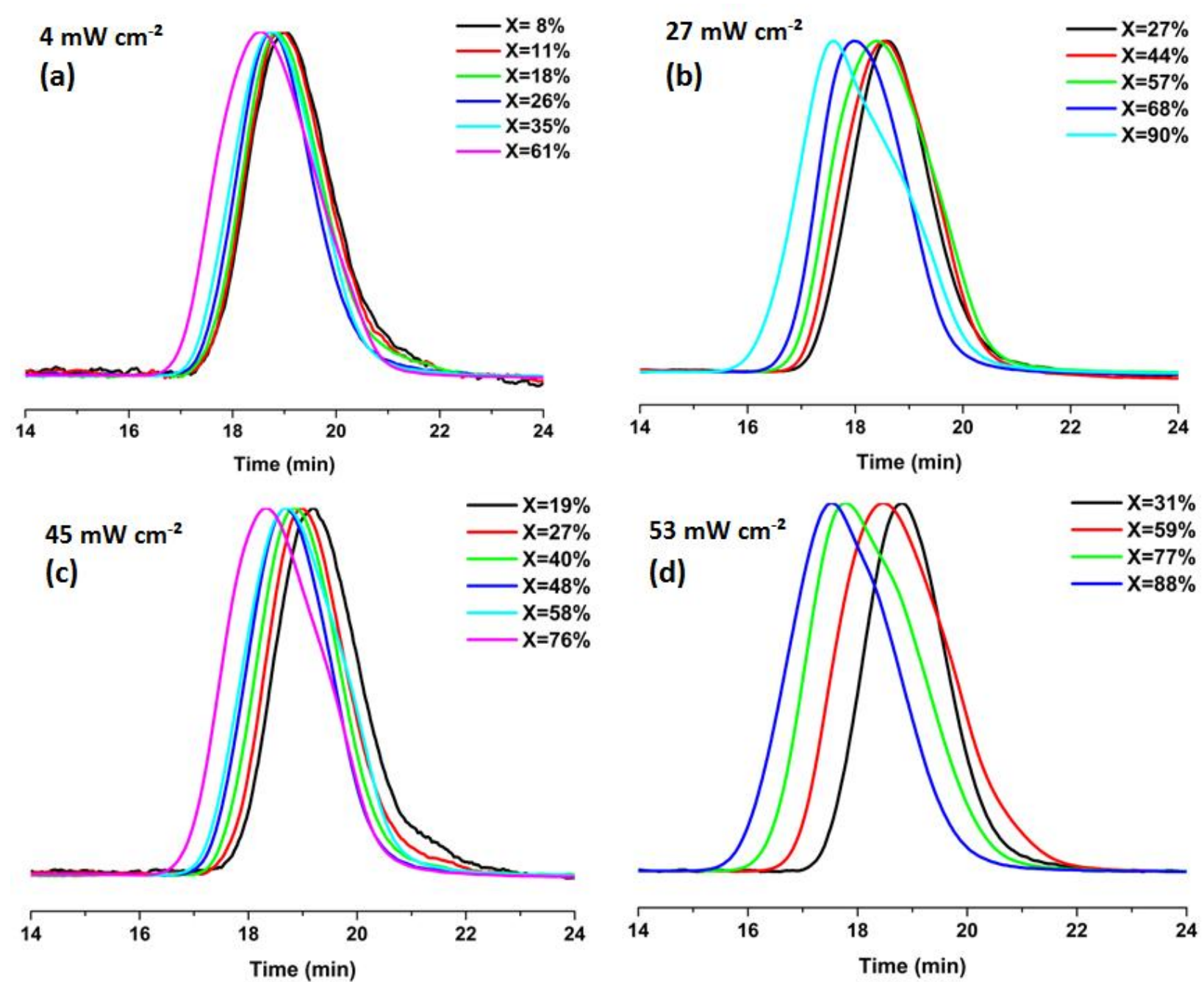

Figure S3. Evolution of PHPMA SEC traces (LS detection, DMF/LiCl at $50^{\circ} \mathrm{C}$ ) with conversion (X). PHPMA were prepared by RAFT polymerization of HPMA at room temperature in DMSO using TTC (1) with various UV lamp intensities: (a) $4 \mathrm{~mW} / \mathrm{cm}^{-2}$, (b) $27 \mathrm{~mW} / \mathrm{cm}^{-2}$, (c) $45 \mathrm{~mW} / \mathrm{cm}^{-2}$ and (d) $53 \mathrm{~mW} / \mathrm{cm}^{-2}$. $[\mathrm{HPMA}]_{0} /[\mathrm{TTC}]_{0}=300 / 1$. 

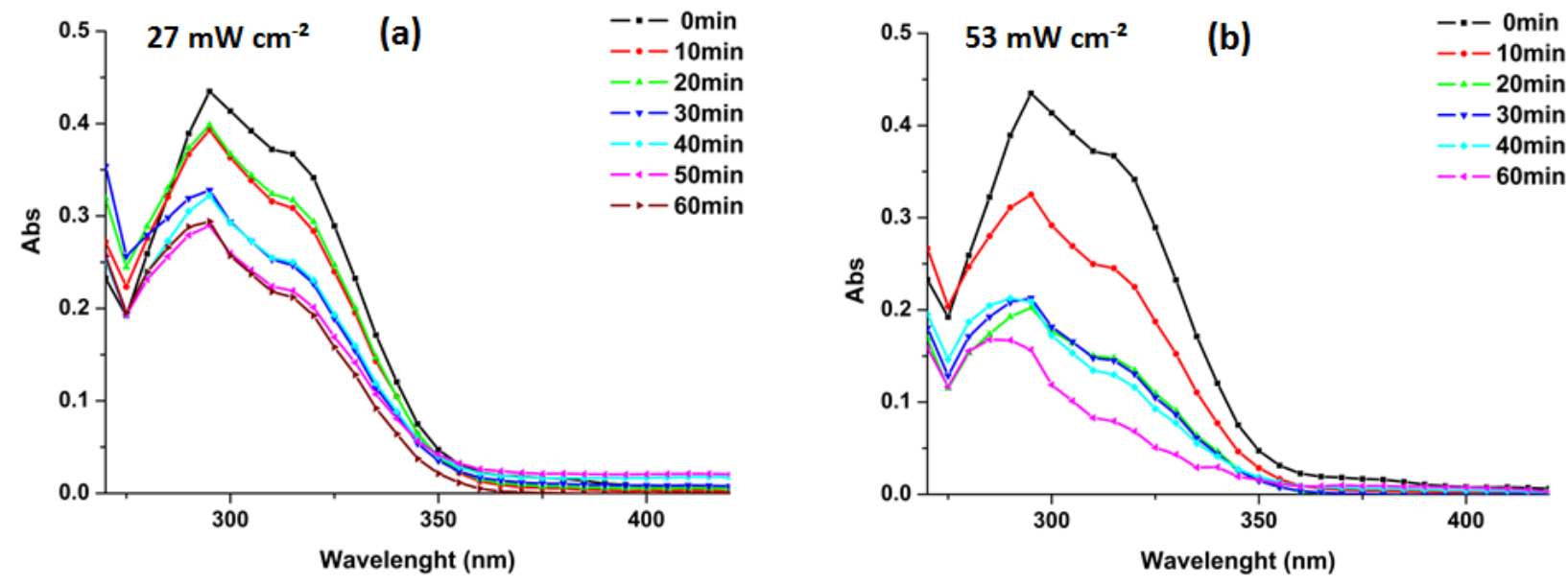

Figure S4. Evolution of UV-Vis absorbance spectra of TTC (1) in DMSO ([TTC]=0.1 mM) under various UV irradiation intensities. (a) $27 \mathrm{~mW} . \mathrm{cm}^{-2}$ and (b) $53 \mathrm{~mW} . \mathrm{cm}^{-2}$ ) at different times.

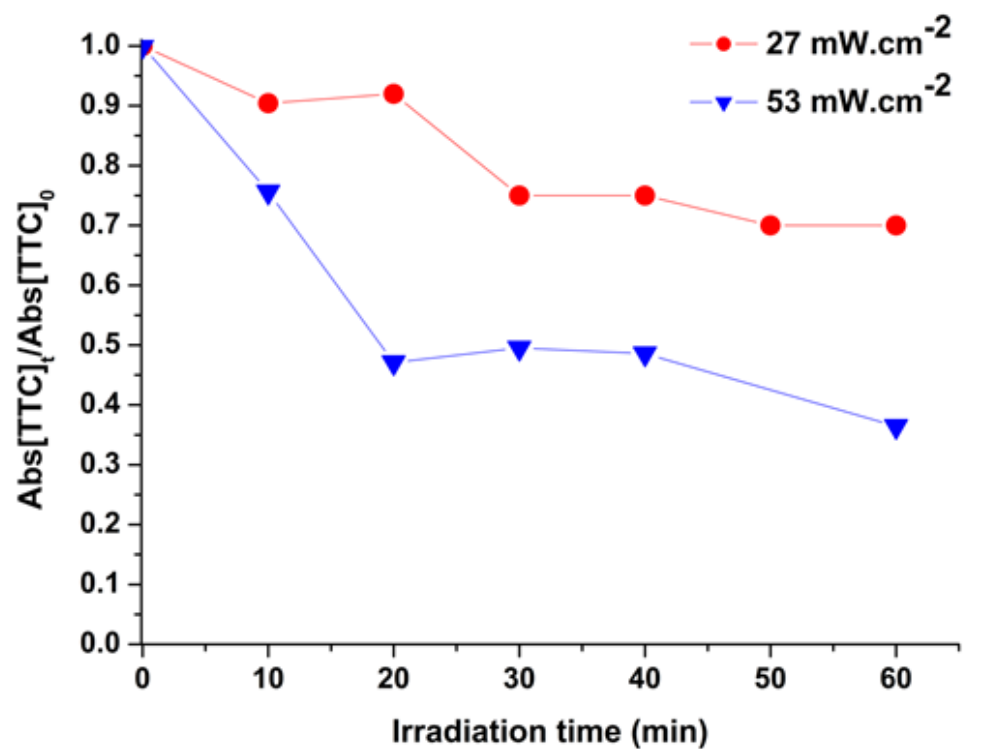

Figure S5. Degradation of TTC (1) in DMSO ([TTC] $=0.1 \mathrm{mM})$ under various UV irradiation intensities $\left(27 \mathrm{~mW} . \mathrm{cm}^{-2}\right.$ and $\left.53 \mathrm{~mW} . \mathrm{cm}^{-2}\right)$, using the absorbance peak at $295 \mathrm{~nm}$ (see figure S4). 


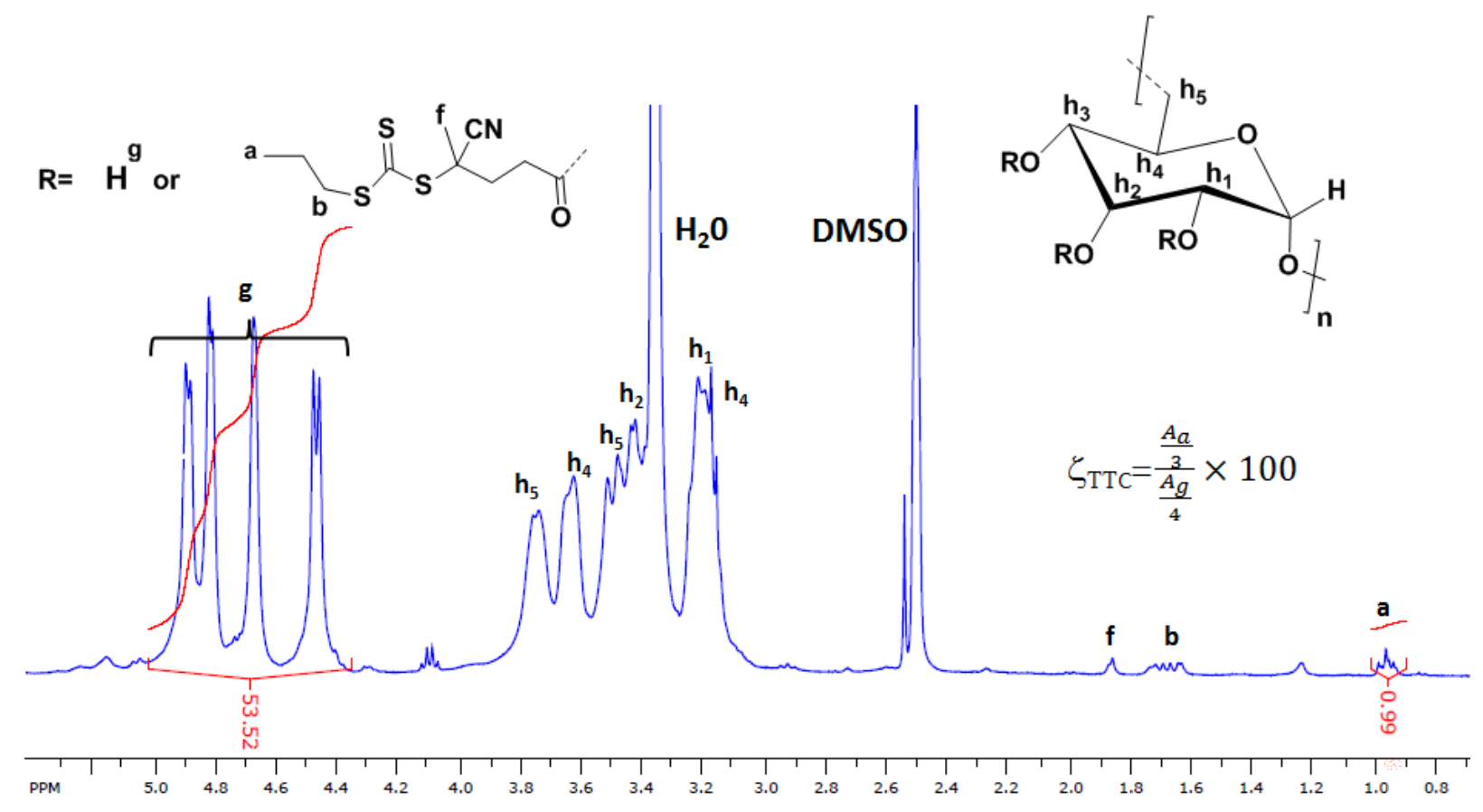

Figure S6. ${ }^{1} \mathrm{H}$ NMR spectrum of Dex-TTC (2). $\zeta_{\pi \mathrm{TC}}$ is the number of TTC moieties per 100 glucopyranosic units (here, $\zeta_{\pi c}=2.5$ ). 


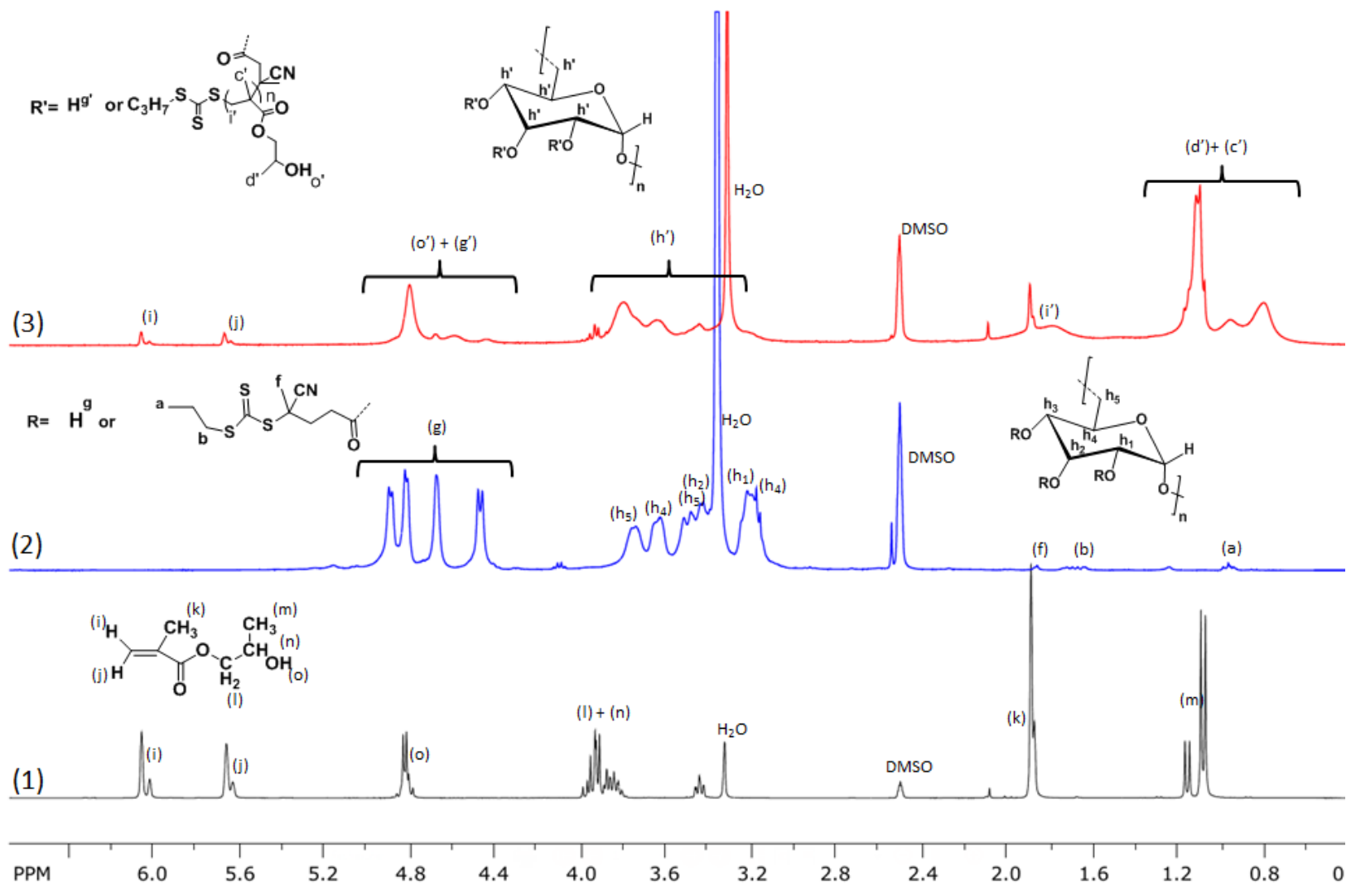

Figure S7. ${ }^{1} \mathrm{H}$ NMR spectra of (1) HPMA monomer, (2) Dex-TTC and crude Dex-g ${ }^{5}-$ PHPMA $_{340}$ glycopolymer prepared by photo-PISA of HPMA in aqueous medium using Dex-TTC as the macro-CTA, at $5 \% \mathrm{w} / \mathrm{w}$ solids content.

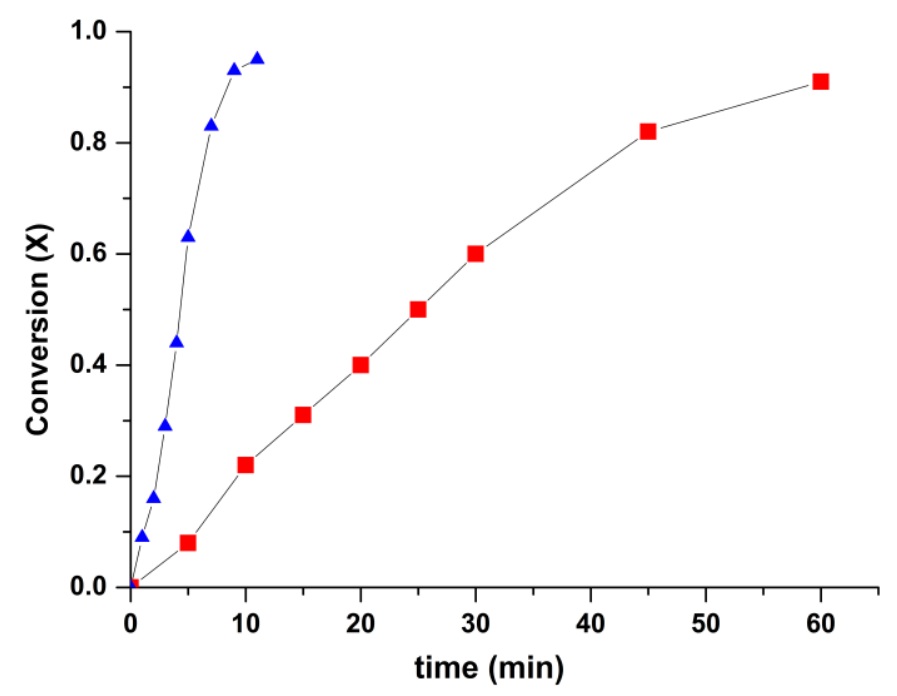

Figure S8. Evolution of conversion with time of aqueous HPMA photo-PISA performed at ( $\square$ ) $5 \% \mathrm{w} / \mathrm{w}$ and $(\boldsymbol{\Delta}) 20 \% \mathrm{w} / \mathrm{w}$ solids content using Dex-TTC as the macro-CTA.[HPMA $]_{0} /[\text { TTC }]_{0}=190 / 1$. 


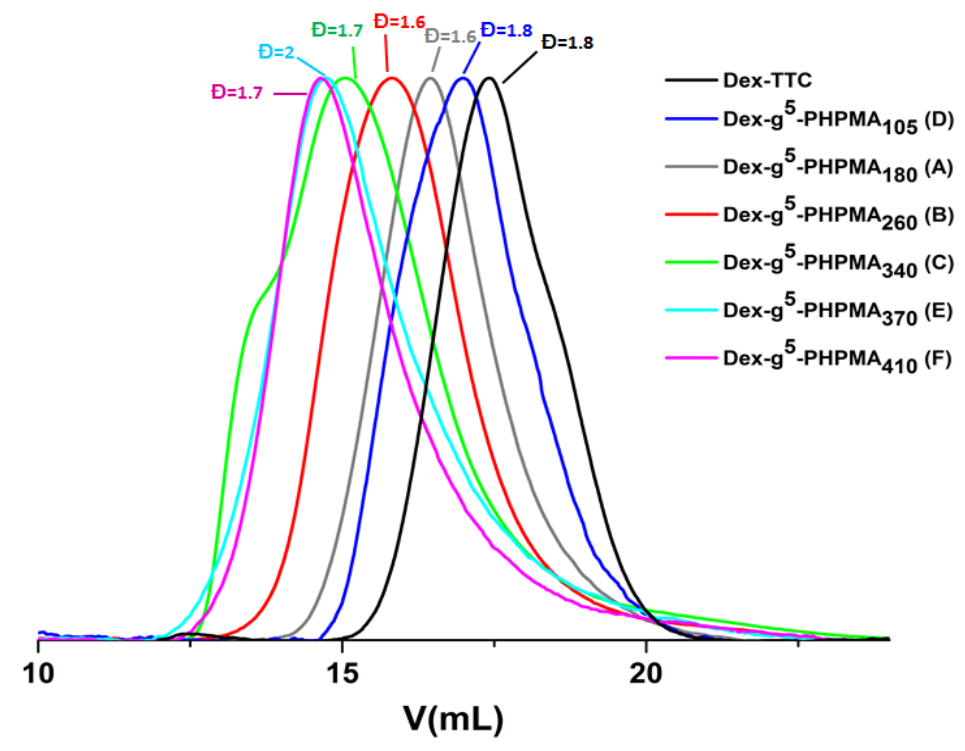

Figure S9. SEC traces of various Dex-g ${ }^{5}-\mathrm{PHPMA}_{\mathrm{y}}$ prepared by aqueous photo-PISA of HPMA using Dex-TTC as the macro-CTA, at a solids concentration of $5 \% \mathrm{w} / \mathrm{w}$ solids content for $(A, B$ and $C)$, and at $20 \% \mathrm{w} / \mathrm{w}$ solids content for (D, E and F).

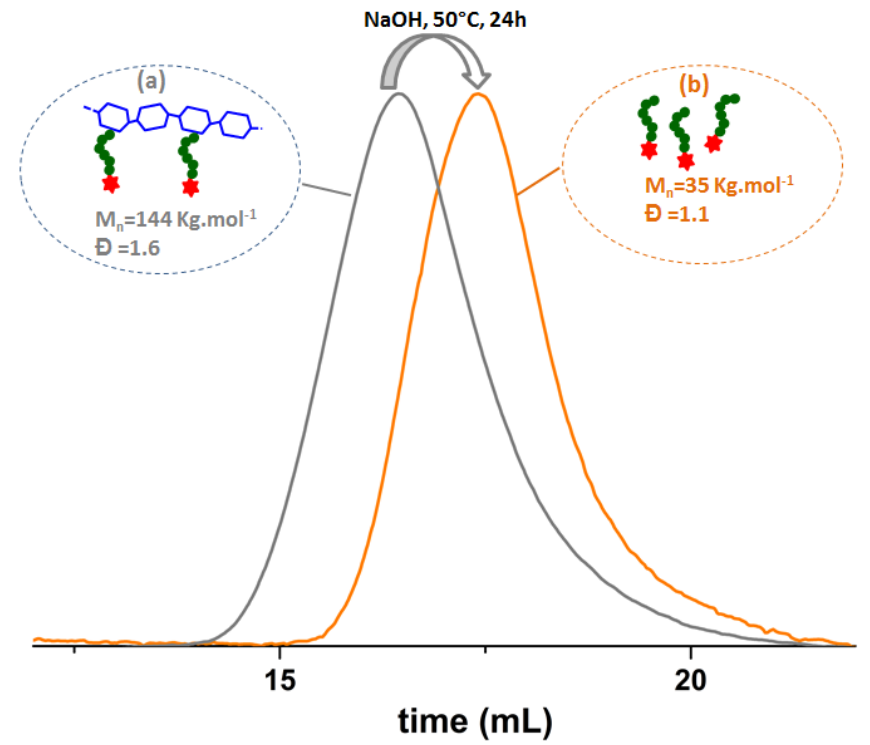

Figure S10. SEC traces of glycopolymers Dex- $g^{5}-\mathrm{PHPMA}_{180}(\mathrm{a})$ and corresponding cleaved PHPMA grafts obtained by treatment in alkaline conditions at $50^{\circ} \mathrm{C}$ during 24 hours. 


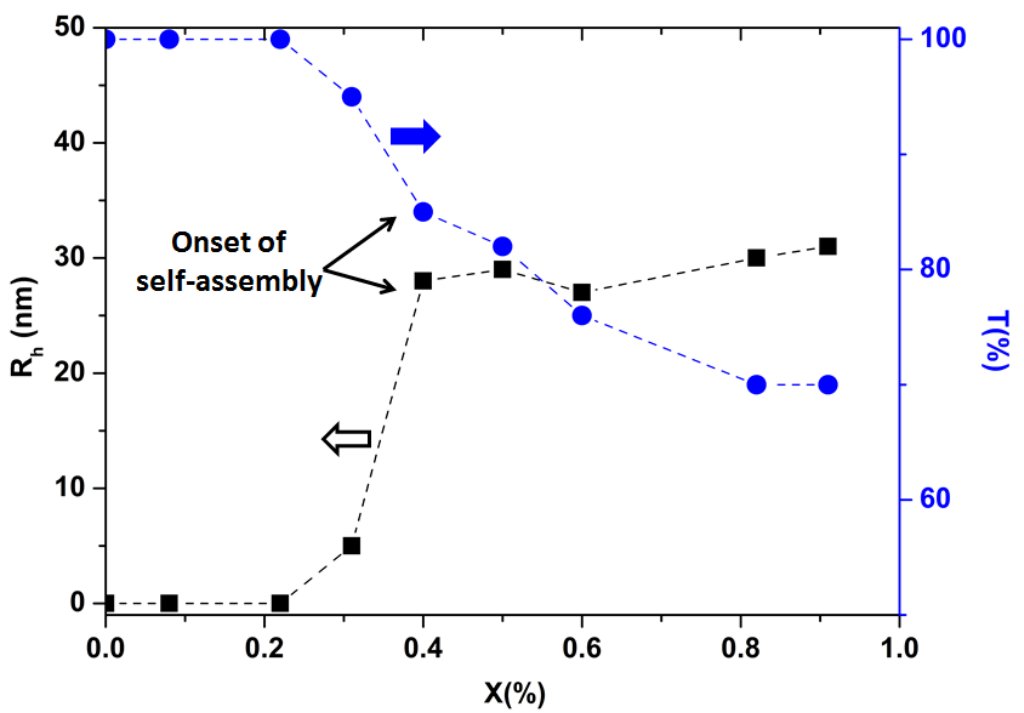

Figure S11. Evolution of $(\square)$ hydrodynamic radii $\left(R_{h}\right)$ and $(\bullet)$ transmittance $(\%)$ of gluco-nanostructure suspensions prepared via aqueous photo-PISA of HPMA using Dex-TTC as the macro-CTA, at a solids concentration of $5 \% \mathrm{w} / \mathrm{w}$ solids content. $[\mathrm{HPMA}]_{0} /[\mathrm{TTC}]_{0}=190 / 1$.

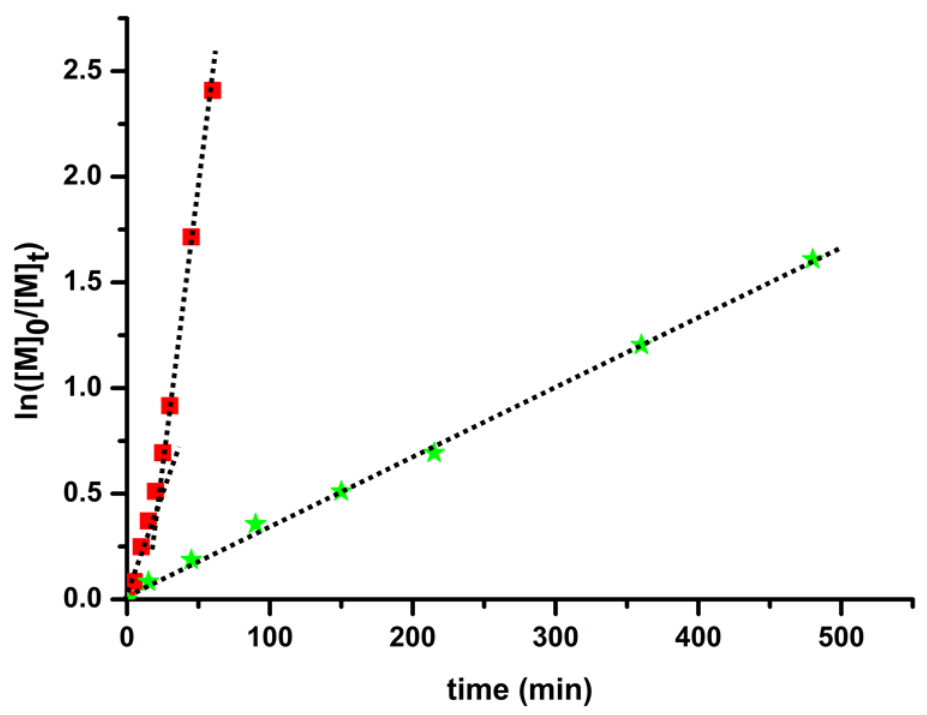

Figure S12. Kinetics of the aqueous HPMA photo-initiated RAFT performed in ( $\square$ ) water and ( ) DMSO at 5\% w/w sellids content using Dex-TTC as the macro-CTA.[HPMA $]_{0} /[\text { TTC }]_{0}=190 / 1$. 
Table S1. Characteristics of Dex-g $-\mathrm{g}^{5}$ PHMA $\mathrm{A}_{\mathrm{y}}$ nanostructures prepared by photo-PISA of HPMA in aqueous medium using Dex-TTC as the macro-CTA, at different solids content (HPMA + Dex-TTC).

\begin{tabular}{|c|c|c|c|c|c|}
\hline Entry & $\begin{array}{l}\text { Solid } \\
\text { Wt(\%) }\end{array}$ & Dex-g ${ }^{5}-$ PHPMA & $\begin{array}{l}\text { Nano-objects } \\
\text { morphologies }\end{array}$ & $\begin{array}{l}\mathbf{R}_{\mathbf{h}}{ }^{(a)} \\
(\mathrm{nm})\end{array}$ & $\begin{array}{c}\mathbf{R}_{\text {TEM }}{ }^{(\mathbf{b})} \\
(\mathrm{nm})\end{array}$ \\
\hline A & & Dex-g - PHPMA $_{180}$ & Micelle & 33 & $21 \pm 3$ \\
\hline B & $5 \%$ & Dex-g $-g^{5}$ PHPMA 260 & Mixture of spherical and oblate micelles & 45 & $40 \pm 13$ \\
\hline C & & Dex-g $-g^{5}-\mathrm{PPMA}_{340}$ & Worm-like micelle & 163 & $225 \pm 50^{(c)}$ \\
\hline D & & Dex-g - PHPMA $_{105}$ & Micelle & 26 & $16 \pm 2$ \\
\hline $\mathbf{E}$ & $20 \%$ & Dex-g - PHPMA 370 & Worm-like micelle & 103 & $450 \pm 50^{(c)}$ \\
\hline $\mathbf{F}$ & & Dex-g $-g^{5}$ PHPMA 410 & Vesicle & 74 & $53 \pm 7$ \\
\hline
\end{tabular}

(a) Hydrodynamic radius obtained from DLS measurements.

(b) Number average radius of nano-objects obtained from TEM images. Statistics were made based on a number of nano-objects between 50 and 100 .

(c) Number average length ( $L$ ) of worm-like nanostructures obtained from TEM images. Statistics were made based on 40 nano-objects. 

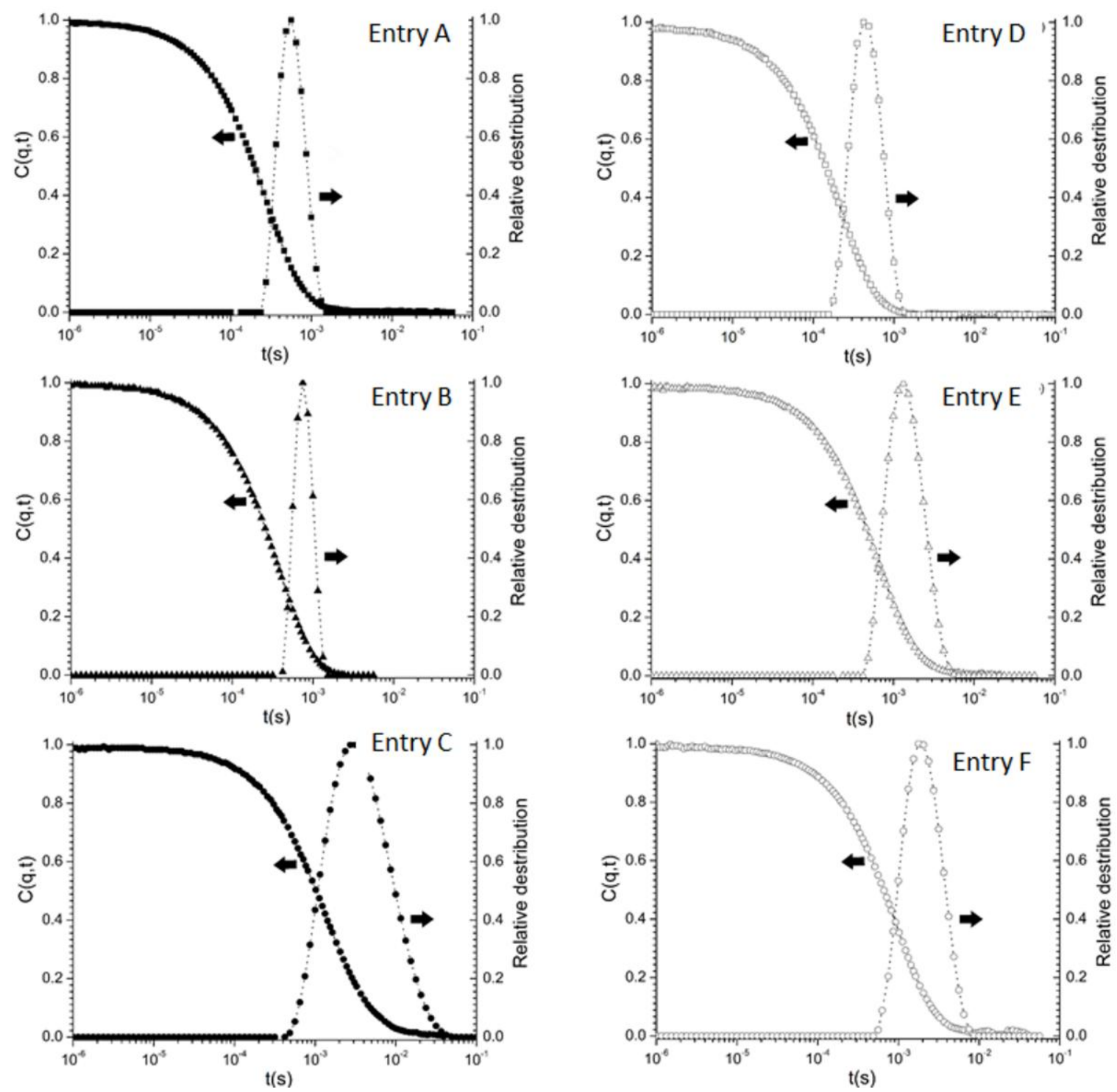

Figure S13. Autocorrelation functions and size distributions recorded at scattering wave vectors $q$ of $1.7 \times 10^{7} \mathrm{~m}^{-1}$ for different Dex- $\mathrm{g}^{5}-\mathrm{PHPMA}_{\mathrm{y}}$ nanostructures prepared by photo-PISA of HPMA in aqueous medium using Dex-TTC as the macro-CTA, at different conditions (see Table S1). 


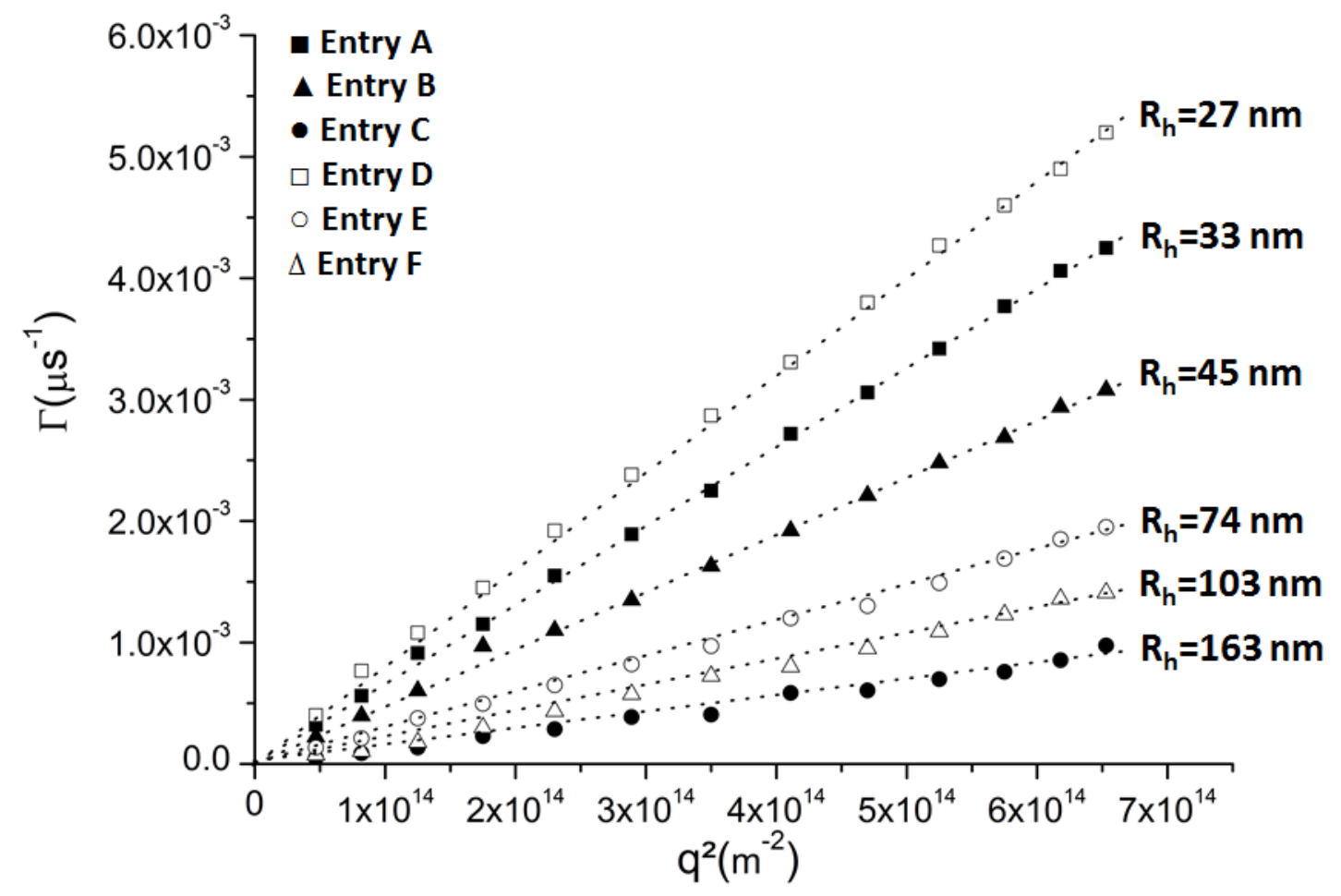

Figure S14. $q^{2}$ dependence of the relaxation rate $(\Gamma)$ for various Dex-g $-\mathrm{PHPMA}_{y}$ nanostructures prepared by photo-PISA of HPMA in aqueous medium using Dex-TTC as the macro-CTA, at different conditions (see Table S1). 

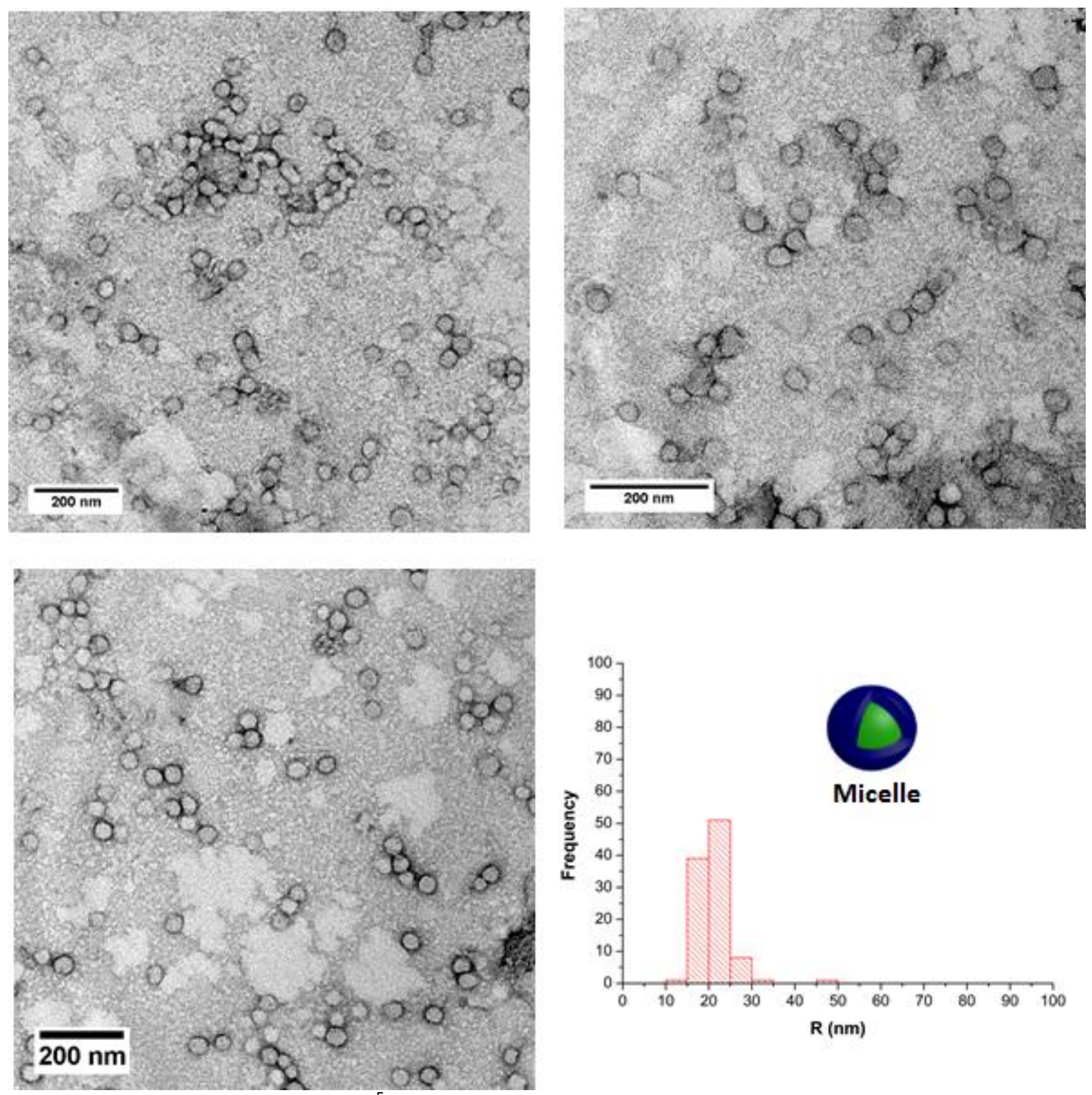

Figure S15. TEM images of Dex-g ${ }^{5}-\mathrm{PHPMA}_{180}$ nanostructures prepared by photo-PISA of HPMA in aqueous medium using Dex-TTC as the macro-CTA, at $5 \% \mathrm{w} / \mathrm{w}$ solids content. The histogram was made from TEM images based on 100 nano-objects. 

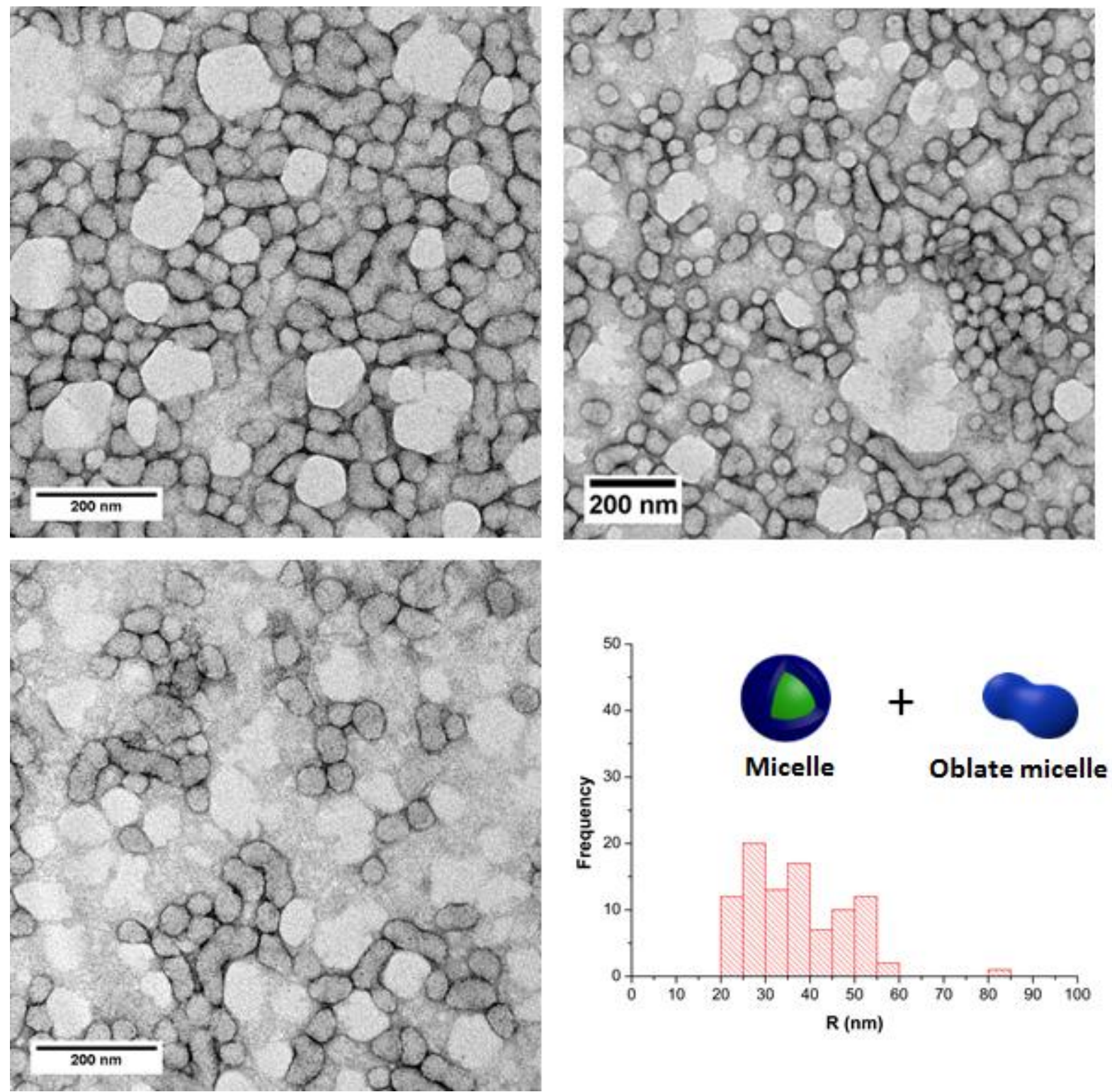

Figure S16. TEM images of Dex-g - $^{5}$ PHPMA $_{260}$ nanostructures prepared by photo-PISA of HPMA in aqueous medium using Dex-TTC as the macro-CTA, at $5 \% \mathrm{w} / \mathrm{w}$ solids content. The histogram was made from TEM images based on 100 nano-objects. 

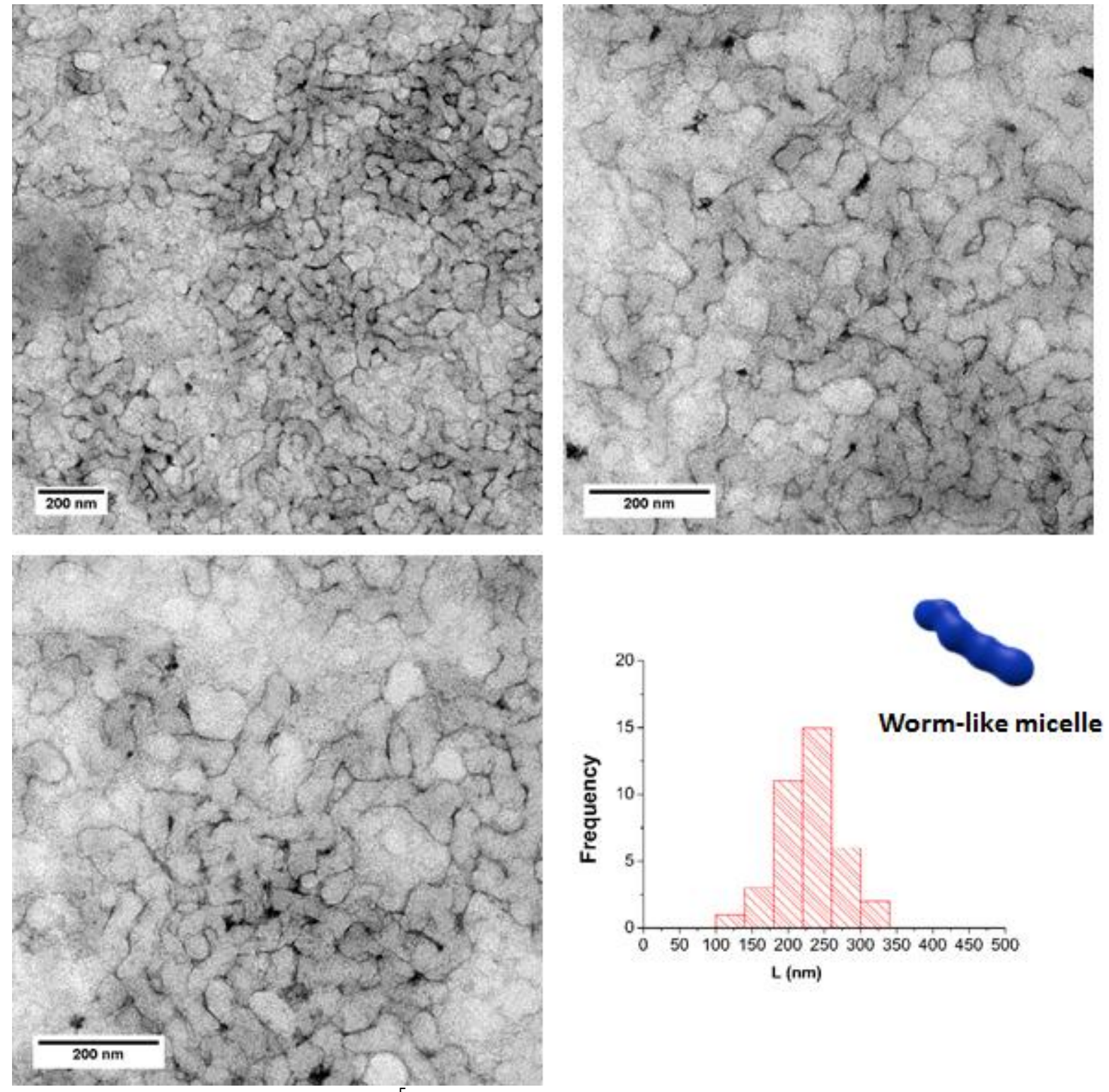

Figure S17. TEM images of Dex-g $-\mathrm{PHPMA}_{340}$ nanostructures prepared by photo-PISA of HPMA in aqueous medium using Dex-TTC as the macro-CTA, at $5 \% \mathrm{w} / \mathrm{w}$ solids content. 

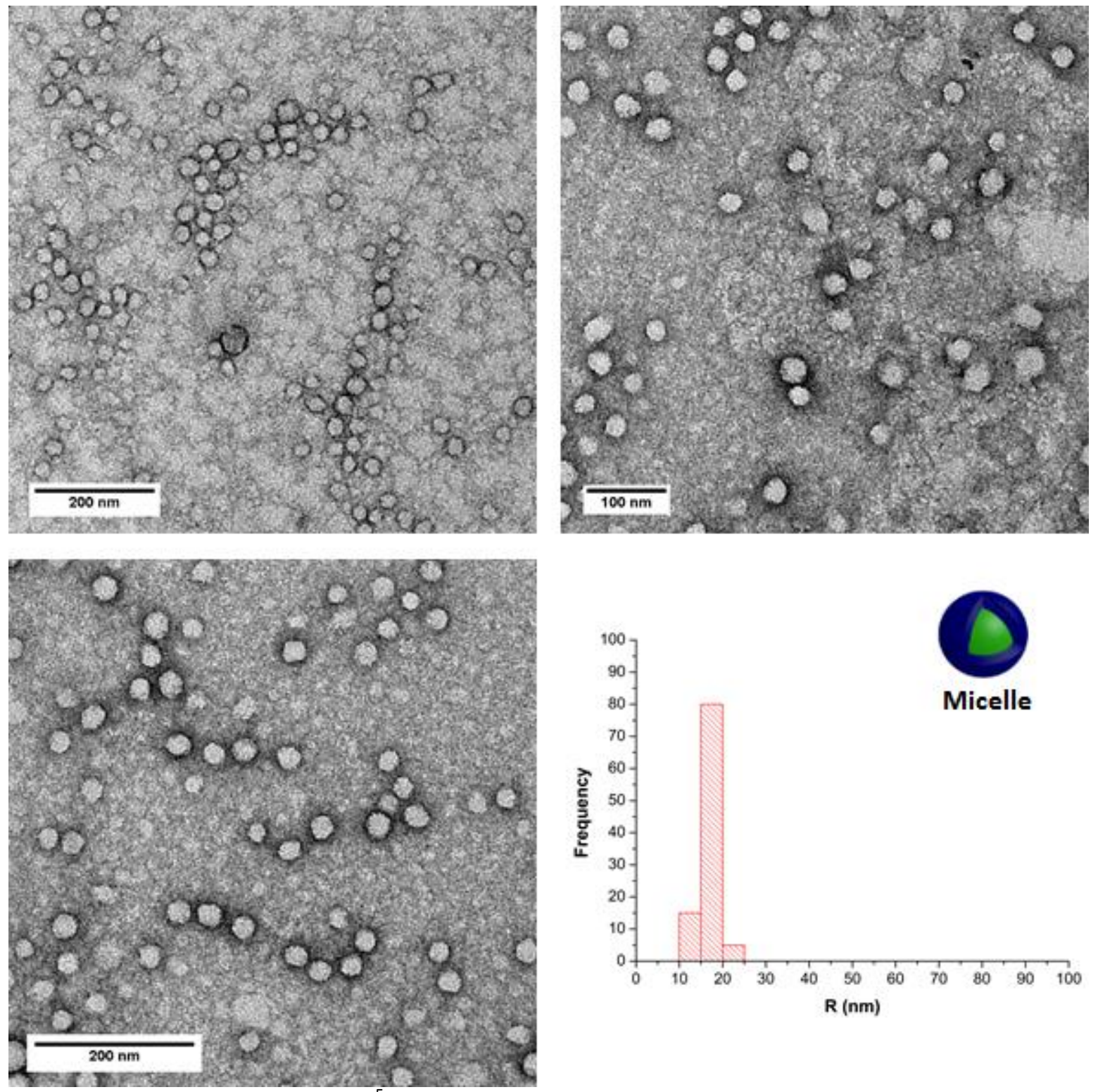

Figure S18. TEM images of Dex-g - PHPMA $_{105}$ nanostructures prepared by photo-PISA of HPMA in aqueous medium using Dex-TTC as the macro-CTA, at $20 \% \mathrm{w} / \mathrm{w}$ solids content. The histogram was made from TEM images based on 100 nano-objects. 

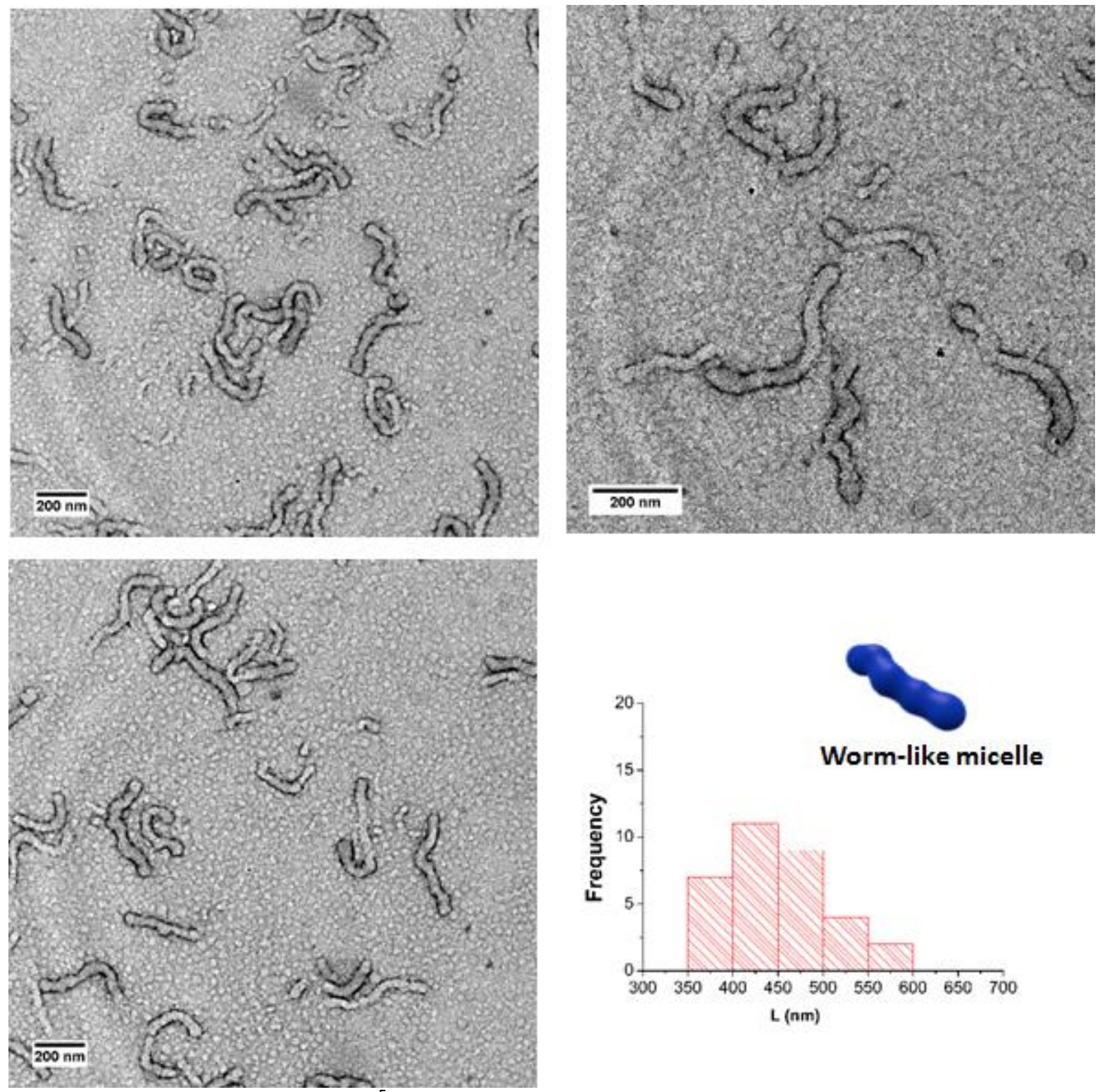

Figure S19. TEM images of Dex- ${ }^{5}-$ PHPMA $_{370}$ nanostructures prepared by photo-PISA of HPMA in aqueous medium using Dex-TTC as the macro-CTA, at $20 \% \mathrm{w} / \mathrm{w}$ solids content. The histogram was made from TEM images based on length ( $L$ ) of 40 nano-objects. 

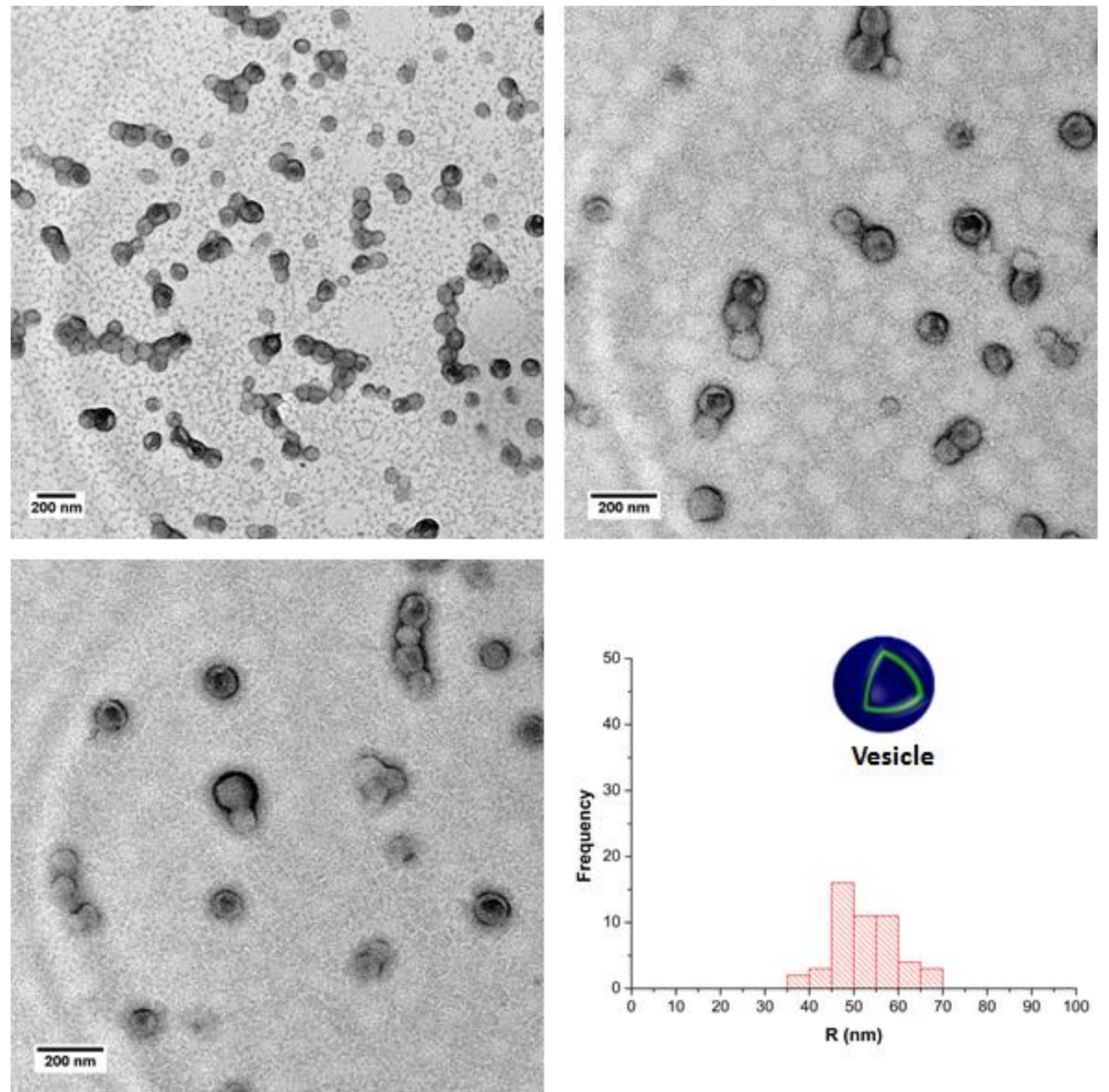

Figure S20. TEM images of Dex-g - PHPMA $_{410}$ nanostructures prepared by photo-PISA of HPMA in aqueous medium using Dex-TTC as the macro-CTA, at $20 \% \mathrm{w} / \mathrm{w}$ solids content. The histogram was made from TEM images based on 50 nano-objects.

\section{References}

(1) (a) G. Moad, Y. K. Chong, A. Postma, E. Rizzardo, S. H. Thang, Polymer 2005, 46, 8458; (b) J. A. Alfurhood, H. Sun, P. R. Bachler, B. S. Sumerlin, Polym. Chem. 2016, 7, 2099.

(2) J. Jakes, J. Collect. Czech. Chem. Commun. 1995, 60, 1781. 